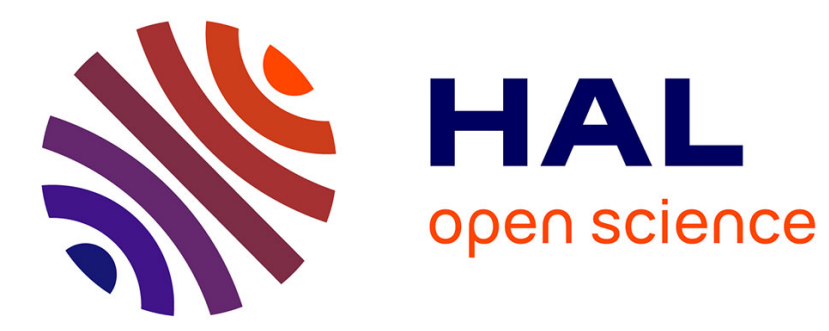

\title{
Experimental and numerical investigation binary mixture mass transfer in a gas - Liquid membrane contactor
}

Valentin Fougerit, Victor Pozzobon, Dominique Pareau, Marc-André

Theoleyre, Moncef Stambouli

\section{To cite this version:}

Valentin Fougerit, Victor Pozzobon, Dominique Pareau, Marc-André Theoleyre, Moncef Stambouli. Experimental and numerical investigation binary mixture mass transfer in a gas - Liquid membrane contactor. Journal of Membrane Science, 2019, 572, pp.1-11. 10.1016/j.memsci.2018.10.042 . hal01959271

\section{HAL Id: hal-01959271 \\ https://hal.science/hal-01959271}

Submitted on 22 Jul 2020

HAL is a multi-disciplinary open access archive for the deposit and dissemination of scientific research documents, whether they are published or not. The documents may come from teaching and research institutions in France or abroad, or from public or private research centers.
L'archive ouverte pluridisciplinaire $\mathbf{H A L}$, est destinée au dépôt et à la diffusion de documents scientifiques de niveau recherche, publiés ou non, émanant des établissements d'enseignement et de recherche français ou étrangers, des laboratoires publics ou privés.

\section{(ㅇ)(1) $\$$}

Distributed under a Creative Commons Attribution - NonCommercial - NoDerivatives 44.0 


\title{
Journal of Membrane Science DOI: 10.1016/j.memsci.2018.10.042
}

\section{Experimental and numerical investigation binary mixture mass transfer in a gas - liquid membrane contactor}

\author{
Valentin Fougerit, Victor Pozzobon*, Dominique Pareau, Marc-André Théoleyre, Moncef Stambouli
}

LGPM, CentraleSupélec, Université Paris-Saclay, SFR Condorcet FR CNRS 3417, Centre Européen de Biotechnologie et de Bioéconomie (CEBB), chemin des Sohettes 51110 Pomacle, France

*Corresponding author: victor.pozzobon@centralesupelec.fr

\section{Abstract}

$\mathrm{CO}_{2}$ removal from binary mixture gaseous streams using hollow fibers membrane module under physical absorption (water) has been investigated. The impact of the gas composition on the mass transfer efficiency was experimentally investigated with a $\mathrm{CO}_{2} / \mathrm{CH}_{4}$ mixture of varying composition ( $y_{\mathrm{CO}_{2}}^{\mathrm{in}}=10-90 \%$ ), covering a wide range of process: natural gas sweetening $\left(5-10 \% \mathrm{CO}_{2}\right)$, post-combustion carbon capture (10-15\% $\left.\mathrm{CO}_{2}\right)$, for biogas upgrading to biomethane $\left(35-50 \% \mathrm{CO}_{2}\right), \ldots$ As expected, the absorbed $\mathrm{CO}_{2}$ flux is increasing with the $\mathrm{CO}_{2}$ partial pressure. Yet the absorbed $\mathrm{CO}_{2}$ flow is multiplied by a factor up to 15 between a 10 and a $90 \%$ inlet $\mathrm{CO}_{2}$ molar fraction, while applying a factor 9 to the inlet flow parameters. This underlines the existence of a non-trivial behavior.

In the meantime, a 2D numerical model describing the absorption of $\mathrm{CO}_{2}$ in a binary gas mixture, based on the internal module geometry and on a local description of the hydrodynamics was proposed. Its development showed that in order to capture the key phenomena, a proper description of mass transfer in transition zone (Knudsen number around 0.34) is mandatory. Implementing this description allowed the model to accurately describe mass transfer over a wide range of gas composition and flow rate, without relying on any fitted parameter.

\section{Highlights}

Absorption of a binary gas mixture was modelled in cross-flow HFMMs

- $\mathrm{CO}_{2}$ absorption ratio is divided by up to a factor 15 in the presence of $\mathrm{CH}_{4}$

- $\quad$ Resistance-in-series has to be adapted to describe HFMM mass transfer

- Transition zone equations are implemented without fitted parameter

- The model predicts mass transfer over a wide range of gas composition and flow rate

\section{Keywords}

Membrane contactor; $\mathrm{CO}_{2}$ absorption; Gas mixture; Diffusion; Mathematical modeling

2 Introduction

Since its development as a technology for the artificial lung, membrane contactor has risen as a promising mass exchanger device for gas-liquid applications. In use today for carbonation in the beverage industry or for deoxygenation for ultrapure water production, it offers promising perspectives in various fields such natural gas sweetening [1] (5-10\% $\left.\mathrm{CO}_{2}\right)$, as post-combustion carbon capture (PCC) [2,3] (10$\left.15 \% \mathrm{CO}_{2}\right)$, biogas upgrading to biomethane [4,5] (35-50\% $\left.\mathrm{CO}_{2}\right)$ or water desalination [6]. This type of mass exchanger offers a high specific area (> $1000 \mathrm{~m}^{2} . \mathrm{m}^{-3}$ ) compared to conventional gas-liquid reactors (Figure 1 ), which paves the way to process intensification.

Thanks to membrane hydrophobic properties, Hollow Fibers Membrane Modules (HFMMs) offer a non-dispersive contact to gasliquid absorption systems with valuable advantages: operational flexibility (independent control of gas and liquid flowrates and pressures), a known interfacial area supported by the membrane, modularity (linear scale-up and ease of maintenance) and compactness [2,10,11]. Nevertheless, the implementation of membrane contactors technologies at an industrial scale is conditioned by a comprehensive understanding of the mass transfer phenomenon and the development of relevant scale-up methodologies. 


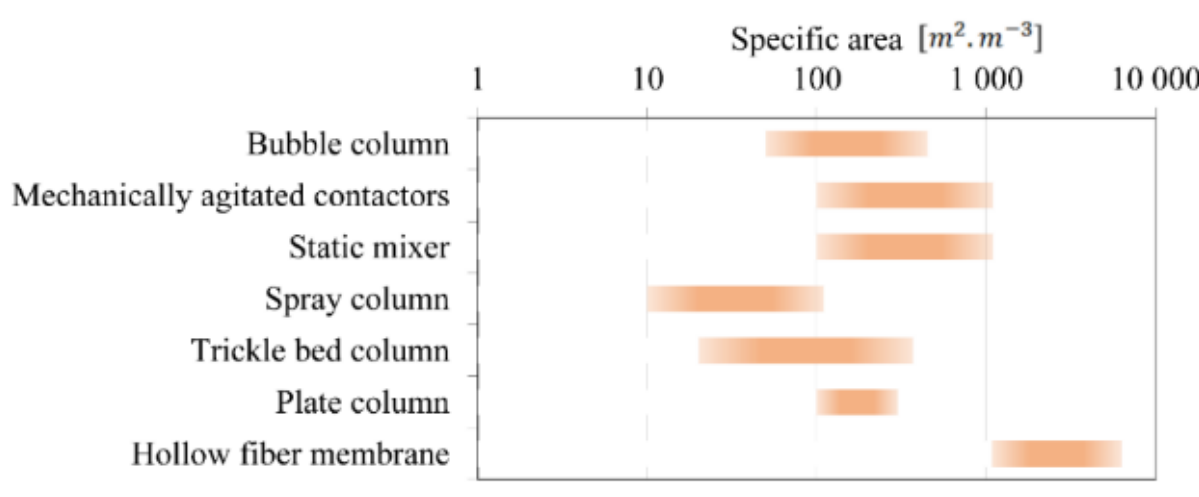

Figure 1 - Specific area of gas-liquid contacting devices (adapted from [7-9])

Indeed nowadays, the $\mathrm{CO}_{2}$ removal stage of a process is led in classical, high volume equipment such as packed column. In this process, two strategies that may not be driven by the same mass transfer limitations coexist: chemical and physical absorption. The selected strategy is dependent on the application:

- $\quad$ For PCC, which is a promising carbon mitigation process since it can easily be implemented to existing power plants to remove $\mathrm{CO}_{2}$ at a concentration 4-15\% in the gas stream [12], chemical absorption is preferred over physical absorption by the use of amine, amino-acids or promoted carbonate solutions $[2,3,13,14]$. The high affinity of these reactants with $\mathrm{CO}_{2}$ allows to selectively react with $\mathrm{CO}_{2}$ and reduce the size of the equipment. Membrane contactors can bring further intensification to this field both at the absorption and the desorption steps. Indeed, polypropylene (PP) and polytetrafluoroethylene (PTFE) hollow fibers demonstrated a 4-fold increase in the overall mass transfer coefficient $\left(K_{G} a\right)$ compared to packed column [15]. Polyvinylidene fluoride (PVDF) membrane was evidenced to be more subject to membrane wetting (and subsequent loss in mass transfer efficiency) than PTFE membranes in the case of monoethanolamine (MEA) and 2-amino-2-methyl-1-propanol (AMP) solutions [16]. Among the amine-solutions, a blend of DEEA/PZ with a molar ratio of 1.50:0.5 demonstrated high absorption and desorption rates in a PTFE HFMM, with a cyclic $\mathrm{CO}_{2}$ capacity of $0.8540 \mathrm{~mol} \mathrm{CO2/L} \mathrm{[17].}$

- Membrane contactors may also find a suitable application in $\mathrm{CO}_{2}$ capture for biogas upgrading to biomethane (35-50 \% $\mathrm{CO}_{2}$ initially), as biogas production units do not necessarily reach a scale large enough to support conventional technologies capital expenditures (CAPEX). A preliminary study demonstrated that chemical absorbent ( $\mathrm{NaOH}$ ) can upgrade over $99 \%$ purity while a $85 \% \mathrm{CH}_{4}$ biomethane was produced using a physical absorbent (water) [4]. The investigation of the process configuration and operating conditions allowed to reach a $98 \%$ methane content with the same membrane module [18]. In this aim, the effect of operating parameters on $\mathrm{CO}_{2}$ removal efficiency with reactive potassium arginate (PA) solutions highlighted the the advantage to operate under turbulent conditions thanks to numerical simulations [19]. Regarding mass transfer limitations, the absorbed $\mathrm{CO}_{2}$ flux in a biogas upgrading to biomethane application is dependent on the liquid velocity for physical absorption while it is controlled by the gas velocity for a chemical system [4]. Under a lower $10 \% \mathrm{CO}_{2}$ fraction in the gas inlet, another study confirmed that $\mathrm{CO}_{2}$ physical absorption is driven by the liquid flowrate [20]. In this reactive case, the mass transfer limitation is reported to be in the liquid phase for physical absorbents, due to a lower $\mathrm{CO}_{2}$ diffusivity in the water than in pure gaseous carbon dioxide $\left(D_{\mathrm{CO}_{2}-\text { water }}^{l}=1.78 \times 10^{-9} \mathrm{~m}^{2} . \mathrm{s}^{-1}\right.$ against $D_{\mathrm{CO}_{2}}^{g}=1.22 \times 10^{-5} \mathrm{~m}^{2} \cdot \mathrm{s}^{-1}$ under atmospheric pressure at $\left.293 \mathrm{~K}\right)$.

Among the $\mathrm{CO}_{2}$ absorption experimental studies involving membrane contactors, the liquid and gas flowrates are the main parameters to be investigated, taking sometimes into account pressure and temperature conditions. The development of a mass transfer model for dense membrane contactors (mass transfer is occurring by diffusion in the membrane polymer) indicated that both the membrane and liquid boundary layer were driving the mass transfer [11]. However, regarding porous membrane contactors, very few studies have systematically investigated the impact of the gas phase composition on the mass transfer efficiency since only specific inlet conditions were considered (5-10\% $\mathrm{CO}_{2}$ for natural gas sweetening, $10-15 \% \mathrm{CO}_{2}$ for $\mathrm{PCC}, 40-50 \% \mathrm{CO}_{2}$ for biogas upgrading to biomethane). The absorbed $\mathrm{CO}_{2}$ flux was experimentally found to increase with the $\mathrm{CO}_{2}$ fraction in the inlet gas using water as the absorbent [21]. For PCC applications, numerical simulations proved that the increase of the $\mathrm{CO}_{2}$ gas fraction in the range $10-20 \% \mathrm{v} / \mathrm{v}$ reduces the carbon capture rate in the case of various amine reactive systems due to the saturation of the absorbent at low concentration [22,23]. The rise in the $\mathrm{CO}_{2}$ partial pressure necessarily enhances the absorbed $\mathrm{CO}_{2}$ flux. However, the impact on the overall mass transfer coefficient $K_{L}$ was not investigated. The gas composition may play a role on the mass transfer mechanism, especially in applications with a significant variation in 
the gas composition such as biogas upgrading to biomethane (the $\mathrm{CO}_{2}$ fraction is varying from $40-50 \%$ to $<3 \%$ ). For instance, the variation of the gas partial pressures was stated to imply a decrease in the selectivity of the process from 166 to 106 [4]. The comparison of experimental studies for $\mathrm{CO}_{2}$ absorption in different applications (Table 1 ) shows that the absorbed $\mathrm{CO}_{2}$ flux $J_{C O_{2}}^{a b s}$ tends to decrease with a decreasing inlet $\mathrm{CO}_{2}$ fraction.

\begin{tabular}{|c|c|c|c|c|c|c|c|}
\hline $\begin{array}{l}\operatorname{Re} \\
\text { f. }\end{array}$ & Conf. & $\begin{array}{c}\text { Membra } \\
\text { ne } \\
\text { material }\end{array}$ & $\begin{array}{l}\text { Membr } \\
\text { ane } \\
\text { area } s \\
{\left[\mathrm{~m}^{2}\right]}\end{array}$ & $\begin{array}{l}\text { Inlet gas } \\
\text { composi } \\
\text { tion }\end{array}$ & $\begin{array}{c}P_{g} \\
{[\text { barg } g]}\end{array}$ & $\begin{array}{c}J_{C_{C 2}}^{a b s} \\
{\left[10^{-4} \operatorname{mol}_{C O_{2} \cdot} \cdot m^{-2} \cdot s^{-1}\right]}\end{array}$ & $\begin{array}{c}\text { Comments (for absorption in } \\
\text { water) }\end{array}$ \\
\hline $\begin{array}{l}{[2} \\
4]\end{array}$ & Abs. & $\begin{array}{c}\text { PP } \\
\text { (Membra } \\
\text { na) }\end{array}$ & 1.4 & Pure $\mathrm{CO}_{2}$ & 0 & $\begin{array}{l}\text { Dry mode: } 11-24 \\
\text { Wet mode: } 9-14\end{array}$ & $\begin{array}{l}J_{C C_{2}}^{a b s} \text { increases with the liquid } \\
\text { flowrate }\end{array}$ \\
\hline $\begin{array}{l}{[2} \\
5]\end{array}$ & $\begin{array}{l}\text { Abs. } \\
\text { Abs./D } \\
\text { es. }\end{array}$ & $\begin{array}{c}\text { PP } \\
\text { (SepraTek } \\
\text { Inc.) }\end{array}$ & 0.25 & $\begin{array}{c}\mathrm{CO}_{2} / \mathrm{CH}_{4} \\
50 / 50\end{array}$ & $\begin{array}{c}1.5- \\
4.5\end{array}$ & $2.9-3.4$ & $\begin{array}{c}J_{C O_{2}}^{a b s} \text { is increasing with the gas } \\
\text { pressure but is almost not impacted } \\
\text { by the increase of the liquid } \\
\text { flowrate }\end{array}$ \\
\hline $\begin{array}{l}{[2} \\
6]\end{array}$ & $\begin{array}{l}\text { Abs./D } \\
\text { es }\end{array}$ & $\begin{array}{c}\text { PP } \\
\text { (Membra } \\
\text { na) }\end{array}$ & 2.8 & $\begin{array}{c}\mathrm{CO}_{2} / \mathrm{CH}_{4} \\
50 / 50\end{array}$ & $2-6$ & 1.3 & $\begin{array}{l}\text { Increasing the gas pressure results } \\
\text { in a limited } J_{C O_{2}}^{a b s} \text { rise, but it decreases } \\
\text { the } \mathrm{CO}_{2} / \mathrm{CH}_{4} \text { selectivity }\end{array}$ \\
\hline [4] & Abs. & $\begin{array}{c}\text { PP } \\
\text { (Membra } \\
\text { na) }\end{array}$ & 0.58 & $\begin{array}{c}\mathrm{CO}_{2} / \mathrm{CH}_{4} \\
40 / 60\end{array}$ & $\mathrm{NS}^{1}$ & $0.8-1.7$ & $\begin{array}{c}J_{C O_{2}}^{a b s} \text { linearly increases with the liquid } \\
\text { flowrate }\end{array}$ \\
\hline $\begin{array}{l}{[2} \\
7]\end{array}$ & Abs. & $\begin{array}{c}\text { PP } \\
\text { (Membra } \\
\text { na) }\end{array}$ & 0.1588 & $\begin{array}{c}\mathrm{CO}_{2} / \mathrm{N} 2 \\
25 / 75\end{array}$ & 0 & $<1.7$ & $\begin{array}{l}\text { Membrane module is used for the } \\
\text { characterization of Henry and } \\
\text { diffusion coefficients }\end{array}$ \\
\hline $\begin{array}{l}{[2} \\
8]\end{array}$ & Abs. & $\begin{array}{c}\text { PP } \\
\text { (Membra } \\
\text { na) }\end{array}$ & 0.09 & $\begin{array}{l}\mathrm{CO}_{2} / \mathrm{N}_{2} \\
20 / 80\end{array}$ & NS & $2-3$ & $\begin{array}{c}J_{C O_{2}}^{a b s} \text { increases with the liquid velocity } \\
\text { No significant effect of the gas } \\
\text { flowrate on } J_{C O_{2}}^{a b s}\end{array}$ \\
\hline $\begin{array}{l}{[2} \\
9]\end{array}$ & Abs. & $\begin{array}{l}\text { ePTFE } \\
\text { (Sumitom } \\
\text { o) / PFA } \\
\text { (Entegris) }\end{array}$ & $\begin{array}{l}0.314 / \\
0.034\end{array}$ & $\begin{array}{c}\mathrm{CO}_{2} / \mathrm{H}_{2} \mathrm{~S} / \\
\mathrm{CH}_{4} \\
5 / 2 / 93\end{array}$ & $1-50$ & $\begin{array}{l}0.09-0.11 / 1.3- \\
1.7 \text { (@ } 1 \text { bar g) }\end{array}$ & $\begin{array}{c}J_{C O_{2}}^{a b s} \text { is slightly increasing with the gas } \\
\text { flowrate } \\
J_{C O_{2}}^{a b s} \text { linearly increases with the gas } \\
\text { pressure in a moderate pressure } \\
\text { range }\end{array}$ \\
\hline
\end{tabular}

Table 1 - Absorbed $\mathrm{CO}_{2}$ flux and effect of operating parameters in various applications involving porous membrane contactors

These discrepant findings suggest a strong need of the scientific community for an unifying modelling approach. In this regard, several authors have addressed the question of mass transfer phenomena in HFMM through numerical modelling. As stated in a previous study [30], 1D and 2D simulations, or even a combination of both, are developed to model gas-liquid mass transfer:

- 1D description along the contactor axis relies on the estimation of mass transfer coefficients in the different phases of the system (gas, membrane, liquid) [16,31,32];

- 2D description of the whole contactor, allowing to describe such configurations such as crow-flows [33-36].

In addition, in order to gain further insights on local mass transfer phenomena, some authors have investigated them at the fiber scale. 2D models are typically used for this kind of approaches. They consider the fiber radial direction to describe mass transfer in the different phases and perform a numeric resolution considering a single fiber $[20,27,28,37-41]$.

The comparison of these two modelling strategies demonstrated that they equally perform for a PCC application $[42,43]$. Though, they still require the membrane mass transfer coefficient $k_{m}$ to be a fitting parameter on which the model is highly dependent $[35,44,45]$. Furthermore, the good performance of the 1D approach for chemical absorption was explained by a relatively flat concentration profile in the liquid phase, which implies a low mass transfer resistance [12]. A higher deviation may appear when considering systems with a low reactivity.

\footnotetext{
${ }^{1}$ Not Specified (NS)
} 
Nevertheless, the above-mentioned models suffer two weaknesses that impair their capability to provide membranes performances further understanding. First, they are lacking a description of the complex shellside hydrodynamics. For instance, some industrial ranges of HFMM (such as the widely used Liqui-Cel ${ }^{\circledR}$ Extra-Flow commercialized by Celgard) have a central diverting baffle: the addition of mixing points enhances the mass transfer [43]. Second, these models are essentially applicable in the operating condition range the membrane mass transfer coefficient $k_{m}$ was fitted.

Therefore, the aims of the current paper are: (1) to experimentally investigate the effect of the inlet gas composition and flow rate on the absorbed $\mathrm{CO}_{2}$ flux and the mass transfer efficiency, thus covering the two regimes highlighted in Table 1, (2) to propose a mechanistic model, without fitted parameter, that could describe mass transfer in HFMM.

\section{Material and methods}

\subsection{Experimental set-up}

The experimental set-up (Figure 2) was designed to monitor the $\mathrm{CO}_{2}$ absorption flux from a $\mathrm{CO}_{2} / \mathrm{CH}_{4}$ mixture, and the upgrading performances of the membrane module under different operating conditions (flowrates and pressures). The inlet gas flowrate $Q_{g}^{\text {in }}$ and its composition are controlled by a 2-way mixer equipped with mass flow controllers (Bronkhorst In-Flow $\mathrm{CTA}$ ). Pure gases ( $\mathrm{CO}_{2}$, $\mathrm{CH}_{4}-\mathrm{Air}$ Liquid AlphaGaz 1 standard $>99.95 \% \mathrm{v} / \mathrm{v}$ ) were used to produce synthetic mixtures. After going through the absorption module, the outlet gas flowrate $Q_{g}^{\text {out }}$ is measured in another mass flow controller (Bronkhorst Low- $\Delta \mathrm{P}$-Flow). The process gas pressure $P_{g}$ is regulated with a PID controller connected to the solenoid valve of the outlet mass flow controller. It takes about 5 minutes for the gas flows and pressure to stabilize at their setpoints. Uncertainties related to thermal mass flowmeters are detailed in Table 3.1.

\begin{tabular}{|c|c|c|}
\hline & In-Flow CTA & Low- $\Delta$ P-Flow \\
\hline Range $\left[N L_{N_{2}} \cdot h^{-1}\right]$ & $100-1000$ & $100-1000$ \\
\hline Precision & $\pm\left(1 \% \mathrm{RD}+1 \% \mathrm{FS}^{2}\right)$ & $\pm(1 \% \mathrm{FS})$ \\
\hline Repeatability & $\pm(0.2 \% \mathrm{FS})$ & $\pm(0.2 \% \mathrm{RD})$ \\
\hline Calibration uncertainty & $\pm 0.5 \% \mathrm{RD}$ & $\pm 0.3 \% \mathrm{RD}$ \\
\hline
\end{tabular}

Table 3.1 - Uncertainties of thermal mass flowmeters

In this open-loop configuration, reverse osmosis (RO) water is flowing counter-currently on the fiber shellside and is discharged after $\mathrm{CO}_{2}$ removal. Two pumps (Iwaki MDT-20LCA and Iwaki MDG-M4S6B) are respectively regulating the pressure $P_{l}$ and the flowrate $Q_{l}$. They are controlled by a pressure transmitter PT 11 and a vortex flowmeter FI (Liqui-View, precision $< \pm 2 \%$ RD) through frequency converters. Liquid $\mathrm{pH}$ is measured in a flow-through fitting positioned after $\mathrm{CO}_{2}$ absorption step (Mettler-Toledo InPro 4262i). Water temperature is regulated at $21 \pm 0.5^{\circ} \mathrm{C}$ with a cryostat through a plate heat exchanger (AlfaLaval).

Gas composition analysis at the gas inlet and outlet are performed with a micro Gas Chromatography (Agilent 490) equipped with 2 columns ( $10 \mathrm{~m}$ Molsieve $5 \AA$ and $10 \mathrm{~m}$ PoraPLOT U). It is combined with a selection valve (VICl 6 -streams selector valve). The pressure of the samples were reduced to 200 mbar g by pressure reducing controllers. Analysis are performed twice to ensure reliable results. The process is evaluated in the steady state regime. Gas composition analyses were performed 30 minutes after the process parameters reached their setpoints. Similar stabilization times are reported in the literature [28]. The gas composition analysis system has a high repeatability $\left(<0.5 \% \mathrm{RSD}^{3}\right)$. The effective uncertainty after considerations on the calibration, the sampling system and the development of analytical sequences is $\pm 0.3 \% v / v$ [46].

\footnotetext{
2 Full-Scale

${ }^{3}$ Relative Standard Deviation
} 


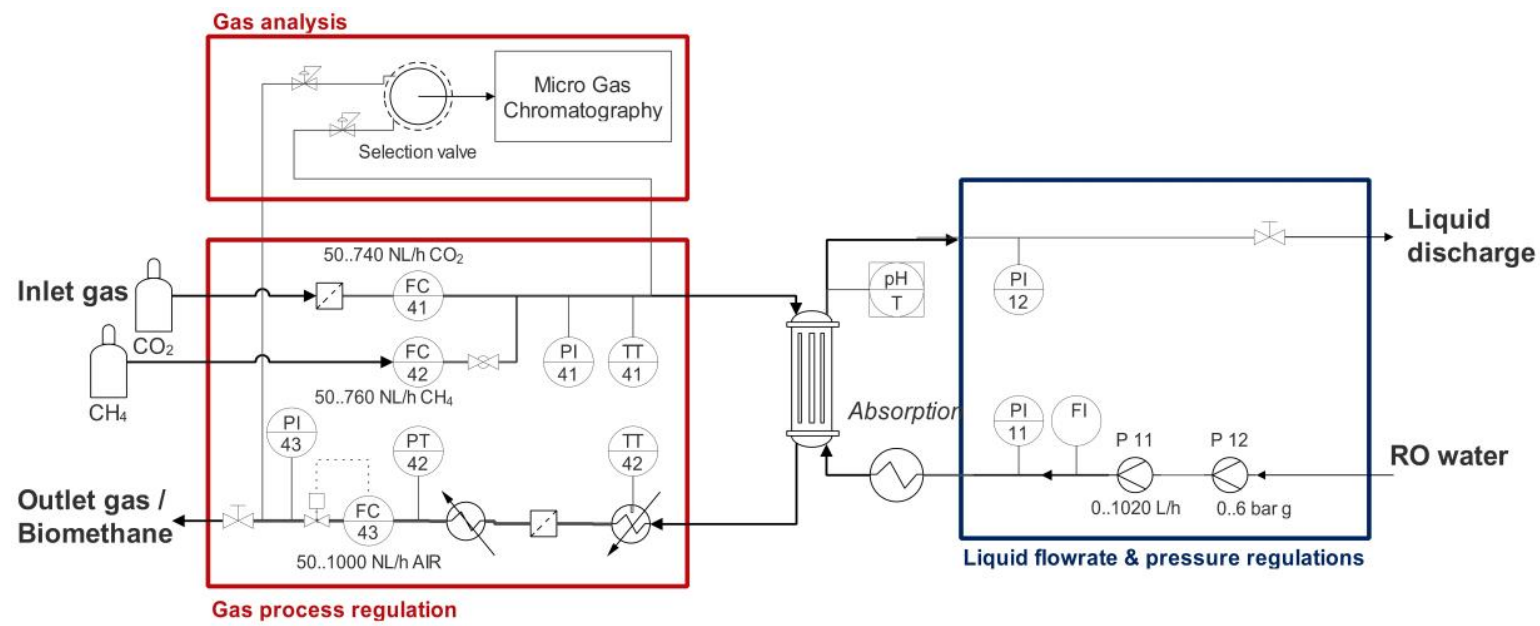

Figure 2 - Experimental set-up for $\mathrm{CO}_{2}$ absorption from a gas mixture in membrane contactor

A 2.5" $\times 8^{\prime \prime}$ Liqui-Cel ${ }^{\circledR}$ Extra-Flow module with hollow fibers of type X-50 was chosen since it is equipped with a central baffle as a mixing element to enhance mass transfer. It is also the smallest item of an available range of industrial contactors. The geometrical features of the module are summarized in Table 2, together with the characteristics of the X-50 hollow fiber. The contact angle between water and the PP membrane material in air was measured to be $121.6^{\circ}$ [47]. The breakthrough pressure of the membrane was calculated to be 51 bar g according to the formula [47]:

$$
\Delta P_{\text {break }}=-\frac{4 \gamma_{\text {water }} \cos \theta}{d_{p, \text { mean }}}
$$

\begin{tabular}{|c|c|c|c|}
\hline \multicolumn{2}{|c|}{ Parameter } & Value & Source \\
\hline \multicolumn{2}{|c|}{ External fiber area $\boldsymbol{S}$} & $1.4 \mathrm{~m}^{2}$ & Membrana \\
\hline \multicolumn{2}{|c|}{ Inner radius of the fiber bundle $\boldsymbol{R}_{\boldsymbol{i}}$} & $1.10 \times 10^{-2} \mathrm{~m}$ & {$[48,49]$} \\
\hline \multicolumn{2}{|c|}{ Outer radius of the fiber bundle $\boldsymbol{R}_{\boldsymbol{o}}$} & $2.32 \times 10^{-2} \mathrm{~m}$ & {$[48]$} \\
\hline \multicolumn{2}{|c|}{$\begin{array}{l}\text { Thickness of the annular gap between the } \\
\text { cartridge and the fiber bundle }\end{array}$} & $3 \times 10^{-3} \mathrm{~m}$ & Membrana \\
\hline \multicolumn{2}{|c|}{ Fiber length $\boldsymbol{L}_{\boldsymbol{f}}$} & $0.203 \mathrm{~m}$ & {$[48,49]$} \\
\hline \multicolumn{2}{|c|}{ Fiber effective length $\boldsymbol{L}_{\boldsymbol{f}}^{\boldsymbol{e f f}}$} & $0.146 \mathrm{~m}$ & {$[48]$} \\
\hline \multicolumn{2}{|c|}{ Number of fibers $\boldsymbol{N}_{f}$} & 10200 & [49] \\
\hline \multirow[t]{2}{*}{ Specific area $\boldsymbol{a}$} & $\begin{array}{l}\text { External fiber area against } \\
\text { effective fiber bundle } \\
\text { volume }\end{array}$ & $7334 \mathrm{~m}^{2} / \mathrm{m}^{3}$ & Calculated \\
\hline & $\begin{array}{c}\text { External fiber area against } \\
\text { module external volume }\end{array}$ & $4089 \mathrm{~m}^{2} / \mathrm{m}^{3}$ & Calculated \\
\hline \multicolumn{2}{|c|}{ Membrane material } & Polypropylene (PP) & Membrana \\
\hline \multicolumn{2}{|c|}{ Inner fiber diameter $\boldsymbol{d}_{\boldsymbol{f i}}[\boldsymbol{\mu m}]$} & 220 & Membrana \\
\hline \multicolumn{2}{|c|}{ External fiber diameter $\boldsymbol{d}_{\boldsymbol{f o}}[\boldsymbol{\mu m}]$} & 300 & Membrana \\
\hline \multicolumn{2}{|c|}{ Porosity ${ }^{4} \varepsilon_{m}[\%]$} & 40 & Membrana \\
\hline \multicolumn{2}{|c|}{ Tortuosity $\boldsymbol{\tau}_{\boldsymbol{m}}[-]$} & 3 & Membrana \\
\hline \multicolumn{2}{|c|}{ Average pore diameter $\boldsymbol{d}_{\boldsymbol{p} \text {,mean }}[\boldsymbol{\mu m}]$} & 0.03 & Membrana \\
\hline \multicolumn{2}{|c|}{$\begin{array}{l}\text { Maximum liquid operating pressure } \\
\left.\text { (for } \boldsymbol{T}<\mathbf{4 0}^{\circ} \boldsymbol{C}\right)[\text { bar } \boldsymbol{g}]\end{array}$} & 7.2 & Membrana \\
\hline
\end{tabular}

Table 2 - Geometric features of the $2.5 \%$ x 8 " Extra-Flow module equipped with type X-50 hollow fibers

\footnotetext{
${ }^{4}$ Data from membrane provider
} 
In order to avoid mass transfer issues related to membrane wetting, the membrane module was dried overnight (>6h) with a constant dry air flow $(900 \mathrm{Nl} / \mathrm{h})$ at atmospheric pressure and room temperature as previously reported [24,30].

\subsection{Experimental operating conditions}

The purpose of this work was to explore $\mathrm{CO}_{2}$ absorption under a wide range of gas composition and flowrates. Three experimental series presented in Table 3 were designed. The gas pressure was set to 5.0 bar $\mathrm{g}$ as the absorption is thermodynamically favored under pressure. The transmembrane pressure is chosen at 0.5 bar $\mathrm{g}$, in accordance with the literature, to avoid gas dispersion into the liquid phase [26]. A typical biogas composition is upgraded to biomethane in the first series, with variation in the gas flowrate to obtain different biomethane quality. Then, the effect of the inlet gas composition is investigated in Series 2 and 3. In Series 2, the flowrates are comparable to Series 1 while the gas-to-liquid ratio is set to its maximum in Series 3 (according to the manufacturer guidelines on applicable flowrates) in order to limit the variation in the gas composition across the module, due to the resulting lower $\mathrm{CO}_{2}$ removal compared to a lower gasto-liquid ratio. The experiments were performed within a single week to avoid experimental deviation.

\begin{tabular}{|c|c|c|c|c|}
\hline \multicolumn{2}{|c|}{ Series } & $\mathbf{1}$ & $\mathbf{2}$ & $\mathbf{3}$ \\
\hline Inlet gas flowrate $\mathbf{Q}_{\mathbf{g}}^{\text {in }}$ & $10^{-5} \mathrm{Nm}^{3} / \mathrm{s}$ & $4.1-23.3$ & 14.6 & 20.8 \\
\hline Water flowrate $\mathbf{Q}_{\mathbf{l}}$ & $10^{-5} \mathrm{~m}^{3} / \mathrm{s}$ & 5.83 & 5.83 & 1.67 \\
\hline Gas pressure $\mathbf{P}_{\mathbf{g}}$ & bar g & 5.0 & 5.0 & 5.0 \\
\hline Liquid pressure $\mathbf{P}_{\mathbf{l}}$ & bar g & 5.5 & 5.5 & 5.5 \\
\hline Liquid temperature $\mathbf{T}_{\mathbf{l}}$ & $\mathrm{K}$ & 294 & 294 & 294 \\
\hline Inlet gas composition $\mathbf{y}_{\mathbf{C}}^{\text {in }}$ & $\% \mathrm{v} / \mathrm{v}$ & 40 & $10-90$ & $40-90$ \\
\hline
\end{tabular}

Table 3 - Range of the operating parameters for the three series of experiments

\subsection{Data processing}

The experiments are assessed under two indicators. The range of the $\mathrm{CO}_{2}$ gas fraction from the inlet to the outlet, $y_{\mathrm{CO}}^{\mathrm{Out}}$, which provides the different gas compositions within the contactor. The absorbed $\mathrm{CO}_{2}$ flux $J_{\mathrm{CO}_{2}}^{a b s}$ is calculated according to Eq. 2:

$$
J_{C O_{2}}^{a b s}=\frac{y_{C O_{2}}^{i n} Q_{g}^{\text {in }}-y_{C O_{2}}^{o u t} Q_{g}^{o u t}}{S}
$$

In the following, the results are displayed in the figures depending on the inlet $\mathrm{CO}_{2}$ flowrate $Q_{g, \mathrm{CO}_{2}}^{i n}$.

\section{$4 \quad$ Mass transfer modelling}

\subsection{Model assumptions}

The present work is an adaptation of a previously published model [30], from the case of pure $\mathrm{CO}_{2}$ physical absorption to the one of a binary mixture. It aims at providing a predictive tool for several $\mathrm{CO}_{2}$ capture applications. The model describes the internal geometry with the central diverting baffle (Figure 3) and predict local mass transfer coefficients from a resistance-in-series model (see Section 4.2). The process is simulated at steady state. In this paper, only the membrane dry mode is considered since it was previously highlighted that wetting has little impact on the $\mathrm{CO}_{2}$ absorbed flux in the considered range of liquid flowrate $\left(<5 \times 10^{-5} \mathrm{~m}^{3} / \mathrm{s}\right)[30]$.

The solvent hydrodynamics in the shellside is described by the Darcy's law. The fiber bundle is considered as an anisotropic porous medium.

$$
\overrightarrow{u_{l}}=-\frac{\overline{\overline{\kappa_{l}}}}{\mu_{l}} \nabla P_{l}
$$

where $\overrightarrow{u_{l}}$ the liquid velocity, $P_{l}$ the liquid pressure, $\mu_{l}$ the dynamic viscosity and $\overline{\overline{\kappa_{l}}}$ the permeability tensor of the porous medium.

Table 4 summarizes the assumptions made for the absorption of pure $\mathrm{CO}_{2}$ only and for the additional ones made for the case of a binary gas mixture. 


\begin{tabular}{|c|c|}
\hline Absorption of pure $\mathrm{CO}_{2}[30]$ & Absorption of a binary mixture \\
\hline $\begin{array}{l}\text { 1. Isothermal operation; } \\
\text { 2. Gas flowing in the lumenside under } \\
\text { constant gas pressure (no pressure drop); } \\
\text { 3. Ideal gas behavior; } \\
\text { 4. Henry's law is valid; } \\
\text { 5. Membrane features (average pore size, } \\
\text { pore size distribution, porosity, thickness, } \\
\text { hydrophobicity and tortuosity) are } \\
\text { uniform in the module; } \\
\text { 6. Membrane properties are constant over } \\
\text { time; } \\
\text { 7. Solvent evaporation is neglected (low } \\
\text { vapor pressure); } \\
\text { 8. No phase entrainment across the } \\
\text { membrane. }\end{array}$ & $\begin{array}{l}\text { 1. The gas phase is a binary gas mixture } \\
\text { 2. Both components are absorbed } \\
\text { 3. Resistance in the gas phase is neglected } \\
\text { against resistance in the liquid phase } \\
\text { 4. No interaction between mixture } \\
\text { components regarding thermodynamic } \\
\text { equilibriums. }\end{array}$ \\
\hline
\end{tabular}

Table 4 - Assumptions of the mass transfer model

\subsection{Mass transfer coefficients}

In our module configuration, the overall mass transfer resistance relative to the liquid phase $K_{L}$ is expressed by [30]:

$$
\frac{1}{K_{L} d_{f o}}=\frac{1}{k_{l} d_{f o}}+\frac{H^{c c}}{k_{m} d_{l n}}+\frac{H^{c c}}{k_{g} d_{f i}}
$$

where $H^{c c}$ is the dimensionless Henry coefficient, $k_{\varphi}$ is the mass transfer coefficient for the phase $\varphi$ and $d_{f o}, d_{f i}, d_{l n}$ are respectively the outer, inner and logarithmic mean diameters of the fibers.

In a first approach, the resistance in the gas phase and gas concentration radial variation in a lumen are neglected against the resistance in the liquid phase. Indeed, under a moderate gas pressure $\left(P_{g}=5\right.$ bar $\left.g\right)$, the diffusion coefficient in the gas phase is 3 orders of magnitude higher that the one in the liquid phase $\left(D_{\mathrm{CO}_{2}}^{g} \sim 10^{-6} \mathrm{~m}^{2} . \mathrm{s}^{-1}\right.$ against $\left.D_{\mathrm{CO}_{2}-\text { water }}^{l} \sim 10^{-9} \mathrm{~m}^{2} . \mathrm{s}^{-1}\right)$. Moreover, the dimensionless Henry coefficients are below $1\left(9.2 \times 10^{-1}\right.$ and $3.4 \times 10^{-2}$ for $\mathrm{CO}_{2}$ and $\mathrm{CH}_{4}$ respectively [50]).

The liquid mass transfer resistances are derived from the calculation of the $S h_{l}$ number according to the Chilton-Colburn correlation optimized in our previous paper:

$$
S h_{l}=3.45 R e_{l}^{0.42} S c_{l}^{\frac{1}{3}}
$$

In this equation, the dimensionless numbers are defined based on local conditions. Indeed, the description of the shellside hydrodynamics in a porous medium displays a non-uniform Reynolds number. The dimensionless numbers and subsequent mass transfer coefficients are then estimated locally:

$$
\begin{gathered}
R e_{l}=\frac{d_{f o}\left\|\vec{u}_{l}\right\|}{v_{l}} \\
S h_{l}=\frac{d_{f o} k_{l}}{D_{l}} \\
S c_{l}=\frac{v_{l}}{D_{l}}
\end{gathered}
$$

The membrane mass transfer coefficient $k_{m}$, calculated under the membrane dry mode, is a combination of molecular and Knudsen diffusions according to Bosanquet's law (details in Appendix) [34]: 


$$
\begin{gathered}
k_{m}=k_{m, d r y}=\frac{D_{g, e f f} \varepsilon_{m}}{\tau_{m} \delta_{m}} \\
\frac{1}{D_{g, e f f}}=\frac{1}{D_{m o l}}+\frac{1}{D_{K n}}
\end{gathered}
$$

\subsection{Model equations}

\subsubsection{Shell side}

The same set of equations is governing the $\mathrm{CO}_{2}$ and the $\mathrm{CH}_{4}$ mass transfer. The $\mathrm{CH}_{4}$ mass balance equation is written:

$$
\nabla \cdot\left(\overrightarrow{u_{l}} \cdot C_{C H_{4}}^{l}\right)=\frac{\varepsilon_{b e d, l}}{\tau_{b e d, l}} D_{C H_{4}}^{l} \Delta C_{C H_{4}}^{l}+r_{C H_{4}}
$$

where $C_{C H_{4}}^{l}$ is the dissolved $\mathrm{CH}_{4}$ concentration in the liquid and $D_{C H_{4}}^{l}$ its diffusivity in the liquid. $\varepsilon_{b e d, l}$ is the shell side porosity. It was calculated as the contactor volume minus the fibers volume using the manufacturer data (Table 2 ). $\tau_{\text {bed,l }}$ is the shell side tortusotiy, it is not known. A value of was taken as a rough estimate and is thought to be valid given the contactor aspect ratio.

The source term $r_{\mathrm{CH}_{4}}$ is the $\mathrm{CH}_{4}$ flowrate transferred from the gas phase to the liquid phase in mol. $m^{-3} . S^{-1}$ :

$$
r_{\mathrm{CH}_{4}}=\varepsilon_{m} K_{L, \mathrm{CH}_{4}} a\left(\mathrm{H}_{\mathrm{CH}}^{\mathrm{CC}} C_{\text {tot }}^{g} y_{\mathrm{CH}_{4}}-C_{C H_{4}}^{l}\right)
$$

where $K_{L, C H_{4}}$ is the local mass transfer coefficient of methane $\left(m . s^{-1}\right), a$ the specific area $\left(m^{2} . m^{-3}\right), H_{C H_{4}}^{c c}$ the dimensionless Henry coefficient, $\mathrm{C}_{\mathrm{CH}_{4}}^{\varphi}$ the concentration of $\mathrm{CH}_{4}$ in the bulk of phase $\varphi$.

\subsubsection{Lumen side}

Since the fiber lumenside is not interconnected, the gas is numerically forced to flow only in the direction of the fibers. Hence a 1D model can be used to describe the gas phase behavior. Similarly to the liquid phase, the gas flow in the lumenside is described by the Darcy's law:

$$
\overrightarrow{u_{g}}=-\frac{\kappa_{g}}{\mu_{g}} \frac{d P_{g}}{d z}
$$

where $\overrightarrow{u_{g}}$ is the gas velocity, $P_{g}$ the gas pressure, $\mu_{g}$ its dynamic viscosity and $\kappa_{g}$ the permeability tensor of the porous medium. The permeability $\overline{\overline{\kappa_{g}}}$ is derived from the Poiseuille equation for a viscous flow in a cylindrical tube: (Eq. 14).

$$
\kappa_{g}=\varepsilon_{b e d, g} \frac{d_{f i}^{2}}{32}
$$

The gas flow is controlled by the mass continuity equation in which the gas-liquid mass transfer terms $r_{i}$ appear:

$$
\frac{d}{d z}\left(\rho_{g} \overrightarrow{u_{g}}\right)=-\kappa_{g} \nabla \cdot\left(\frac{C_{t o t}^{g} M_{g}}{\mu_{g}} \frac{d P_{g}}{d z}\right)=-\sum_{i} r_{i} M_{i}
$$

where $\rho_{g}$ is the gas density, $C_{t o t}^{g}$ the total gas molar concentration, $r_{i}$ the source term for species i, $M_{g}$ and $M_{i}$ the respective molar masses of the gas phase mixture and species $i$.

The mass balance equation on the gas phase for component i controls the evolution of its molar fraction $y_{i}$ :

$$
\frac{d}{d z}\left(\overrightarrow{u_{g}} \cdot C_{t o t}^{g} y_{i}\right)=\frac{\varepsilon_{b e d, g}}{\tau_{b e d, g}} D_{i}^{g} C_{t o t}^{g} \frac{d^{2} y_{i}}{d z^{2}}-r_{i}
$$

where $\varepsilon_{b e d, g}$ (calculated with manufacturer data) and $\tau_{b e d, g}$ (taken equal to 1 ) are the porosity and tortuosity of the fiber bed regarding the gas phase, $y_{i}$ is the gas molar fraction, $D_{i}^{g}$ the diffusion coefficient in the gas mixture and $r_{i}$ the source term of species i. $C_{t o t}^{g}$ is considered constant along the membrane module as no pressure drop has been observed during the experiments $(\Delta P<0.05$ bar). 
The axial geometry of the membrane module allows the reduction to a two dimensions problem. Two different meshes are superimposed to respectively describe the gas and the liquid phases (Figure 3). The model simulates the outlet compositions and flowrates from input parameters (inlet composition and flowrates, operating pressures and temperatures).
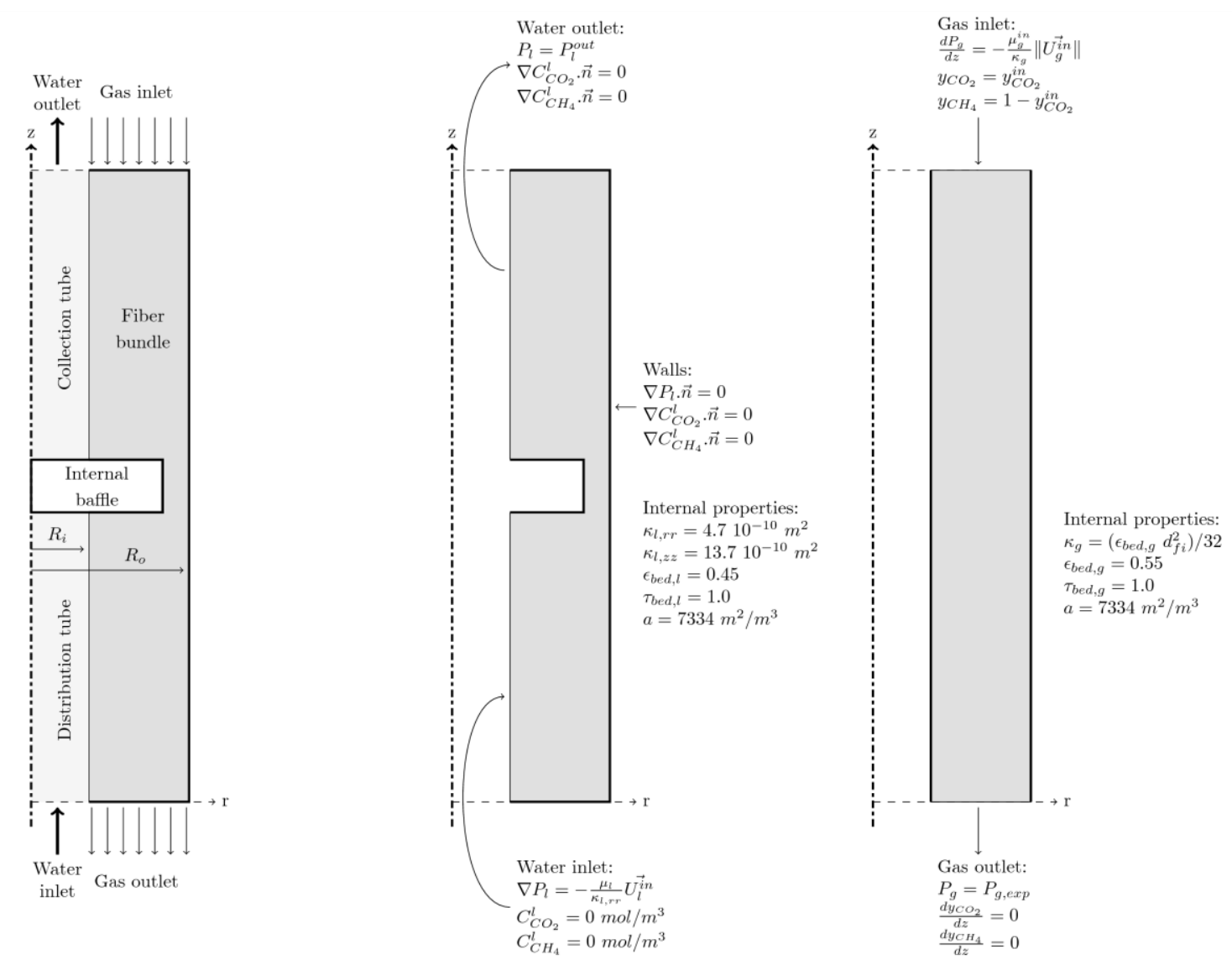

Figure 3 - Modulle geometry with model inlet and boundary conditions (a) Internal module geometry (b)
Liquid flow on the shellside (c) Gas flow on the lumenside

The model was implemented under the open source CFD framework OpenFOAM. The same mesh was used for both the liquid and the gas phases: the convergence was achieved using a 9000 square cells mesh. Mass imbalance was verified to be below $10^{-4}$. The solver tolerance was set to $10^{-9}$ for all the numerical fields. The runtime for a single simulation is about 20 minutes on a single thread (Intel Core i7-4910 MQ Haswell at $2.90 \mathrm{GHz}, 16 \mathrm{G}$ DDR3 $1600 \mathrm{MHz}$ ).

\section{Comparison of experimental and numerical results}

The experimental results are presented in Table 5 . In the first series, the biogas mixture $\left(40 \% \mathrm{CO}_{2}, 60 \% \mathrm{CH}_{4}\right)$ is further upgraded from $y_{\mathrm{CO}_{2}}^{\mathrm{out}}=28.1 \%$ down to $1.9 \%$ as the gas flowrate $Q_{g}^{i n}$ decreases. The gas composition is then highly variable. In the Series 2 with a varying inlet gas composition, the $\mathrm{CO}_{2}$ gas fraction decreases by a maximum of 12.3 points between the inlet and outlet. In the Series 3 , this variation is minimized with a high gas-to-liquid ratio: the gas partial pressures are almost constant across the mass exchanger. The results on the absorbed $\mathrm{CO}_{2}$ fluxes are discussed in the following paragraphs. In the meantime, the corresponding simulations were run to validate the model. The relative numerical error on the $\mathrm{CO}_{2}$ absorbed flux is calculated according to:

$$
\varepsilon_{r e l, J_{\mathrm{CO}_{2}}}=\frac{J_{\mathrm{CO}_{2}, \mathrm{num}}^{\mathrm{abs}}-J_{\mathrm{CO}_{2}, \exp }^{\mathrm{bbs}}}{J_{\mathrm{CO}_{2}, \exp }^{a b s}}
$$




\begin{tabular}{|c|c|c|c|c|c|c|}
\hline Series & $\begin{array}{c}\mathbf{Q}_{\mathrm{g}}^{\text {in }} \\
\left(10^{-5}\right. \\
\mathrm{Nm}^{3} / \\
\mathrm{s})\end{array}$ & $\begin{array}{c}\mathrm{Q}_{\mathrm{l}} \\
\left(10^{-5}\right. \\
\left.\mathrm{m}^{3} / \mathrm{s}\right)\end{array}$ & $\mathbf{y}_{\mathrm{CO}_{2}}^{\text {in }}$ & $\mathbf{y}_{\mathrm{CO}_{2}}^{\text {out }}$ & $\mathrm{CO}_{2}$ removal rate & {$\left[10^{-4} \mathrm{~mol}_{\mathrm{CO}_{2}}^{\left.\mathrm{J}_{\mathrm{CO}_{2}}^{\mathrm{abs}} \cdot \mathrm{m}^{-2} \cdot \mathrm{s}^{-1}\right]}\right.$} \\
\hline \multirow{6}{*}{1} & 4.1 & \multirow{6}{*}{5.83} & \multirow{6}{*}{40} & 1.9 & $101 \%$ & 5.24 \\
\hline & 5.8 & & & 5.4 & $95 \%$ & 7.07 \\
\hline & 9.9 & & & 15.2 & $78 \%$ & 9.84 \\
\hline & 14.6 & & & 22.5 & $61 \%$ & 11.4 \\
\hline & 18.7 & & & 26.1 & $51 \%$ & 12.2 \\
\hline & 23.3 & & & 28.1 & $45 \%$ & 13.5 \\
\hline \multirow{4}{*}{2} & \multirow{4}{*}{14.6} & \multirow{4}{*}{5.83} & 10 & 6.3 & $40 \%$ & 1.88 \\
\hline & & & 40 & 27.7 & $46 \%$ & 8.53 \\
\hline & & & 70 & 59.6 & $46 \%$ & 15.0 \\
\hline & & & 90 & 80.2 & $68 \%$ & 28.3 \\
\hline \multirow{3}{*}{3} & \multirow{3}{*}{20.8} & \multirow{3}{*}{1.67} & 40 & 34.5 & $21 \%$ & 5.57 \\
\hline & & & 70 & 65.7 & $26 \%$ & 12.0 \\
\hline & & & 90 & 87.6 & $29 \%$ & 17.1 \\
\hline
\end{tabular}

Table 5 - Experimental results for the absorption of $\mathrm{CO}_{2}$ in a $\mathrm{CO}_{2} / \mathrm{CH}_{4}$ mixture

\subsection{Influence of the flowrate ratio}

The absorbed $\mathrm{CO}_{2}$ fluxes both from experimental data and numerical simulations are compared in Figure 4 for the Series 1 . The continuous line is the equivalent inlet $\mathrm{CO}_{2}$ flux, which is then the maximum absorbed $\mathrm{CO}_{2}$ flux. The experimental absorbed $\mathrm{CO}_{2}$ flux is increasing with the inlet gas flowrate according to a square root function while the numerical flux follows a linear trend. As the inlet gas flow increases, the $\mathrm{CO}_{2}$ concentration will be higher, thus increasing the mass transfer potential. The two first points of this series are not discriminant regarding mass transfer efficiency since nearly all the inlet $\mathrm{CO}_{2}$ flow is removed ( 99 and $95 \%$ respectively). A variation in the mass transfer coefficient will not be observed for these experiments. However, as the inlet $\mathrm{CO}_{2}$ flowrate is increasing proportionally to the total gas flowrate, the relative numerical error is increasing from $-8 \%$ at $Q_{g}^{\text {in }}=4.1 \times 10^{-5} \mathrm{Nm}^{3} / \mathrm{s}$ to $75 \%$ at $Q_{g}^{\text {in }}=$ $23.3 \times 10^{-5} \mathrm{Nm}^{3} / \mathrm{s}$.

Since the numerical model had been previously validated for the absorption of pure $\mathrm{CO}_{2}$, the observed deviation between the numerical and experimental results may be explained by a lower mass transfer efficiency in the presence of methane.

\subsection{Influence of the inlet gas composition}

The absorbed $\mathrm{CO}_{2}$ flux is increasing with the $\mathrm{CO}_{2}$ fraction at the gas inlet, for both Series 2 and 3 (Figure 5). With a higher $\mathrm{CO}_{2}$ concentration, the mass transfer potential increases leading to a rise in the absorbed $\mathrm{CO}_{2}$ flux. In Series 2, is multiplied by a factor 15 between the two extreme concentrations ( and for and respectively). Yet this increase by a factor 15, while applying a factor 9 to the inlet parameters, underlines the existence of a non-trivial behavior. 


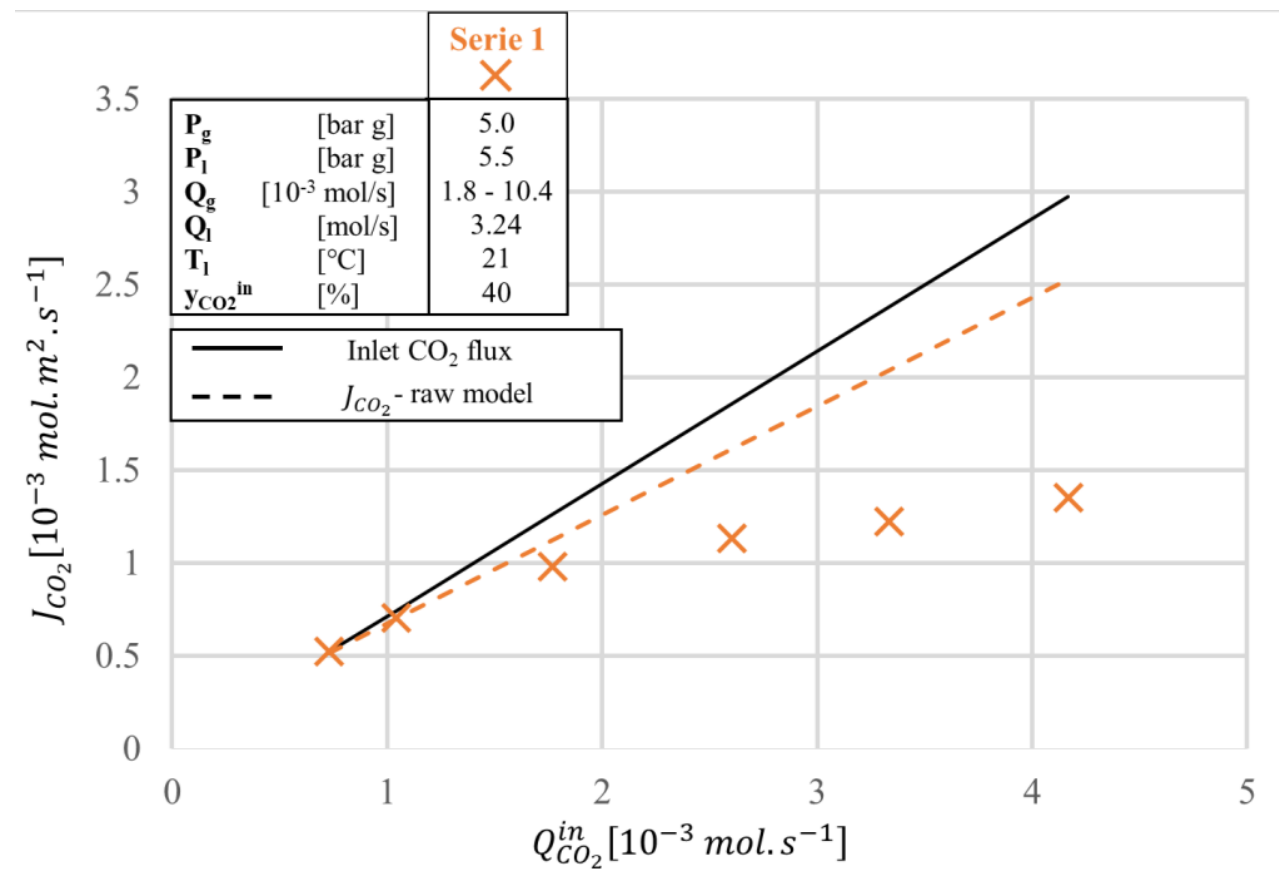

Figure 4 - Influence of the inlet gas flowrate on the absorbed $\mathrm{CO}_{2}$ flux

The deviation between the experimental and numerical absorbed $\mathrm{CO}_{2}$ fluxes is confirmed for both Series 2 and 3 . In Series 2, the relative error on the absorbed flux is increasing as the inlet $\mathrm{CO}_{2}$ fraction is reduced: the deviation of $20 \%$ at $y_{\mathrm{CO}_{2}}^{\text {in }}=90 \%$ rise up to 135 $\%$ at $y_{\mathrm{CO}_{2}}^{\mathrm{in}}=10 \%$. This trend is confirmed with Series 3 where the relative error on $J_{\mathrm{CO}_{2}}^{\mathrm{abs}}$ is rising with a decreasing inlet concentration (from $33 \%$ to $79 \%$ for an inlet $\mathrm{CO}_{2}$ fraction of 40 and $90 \%$ respectively). In this series, the gas-to-liquid ratio was maximized to observe a small variation in the partial gas pressures (Table 5 ). The high relative error observed implies that the model mass transfer description is incomplete.

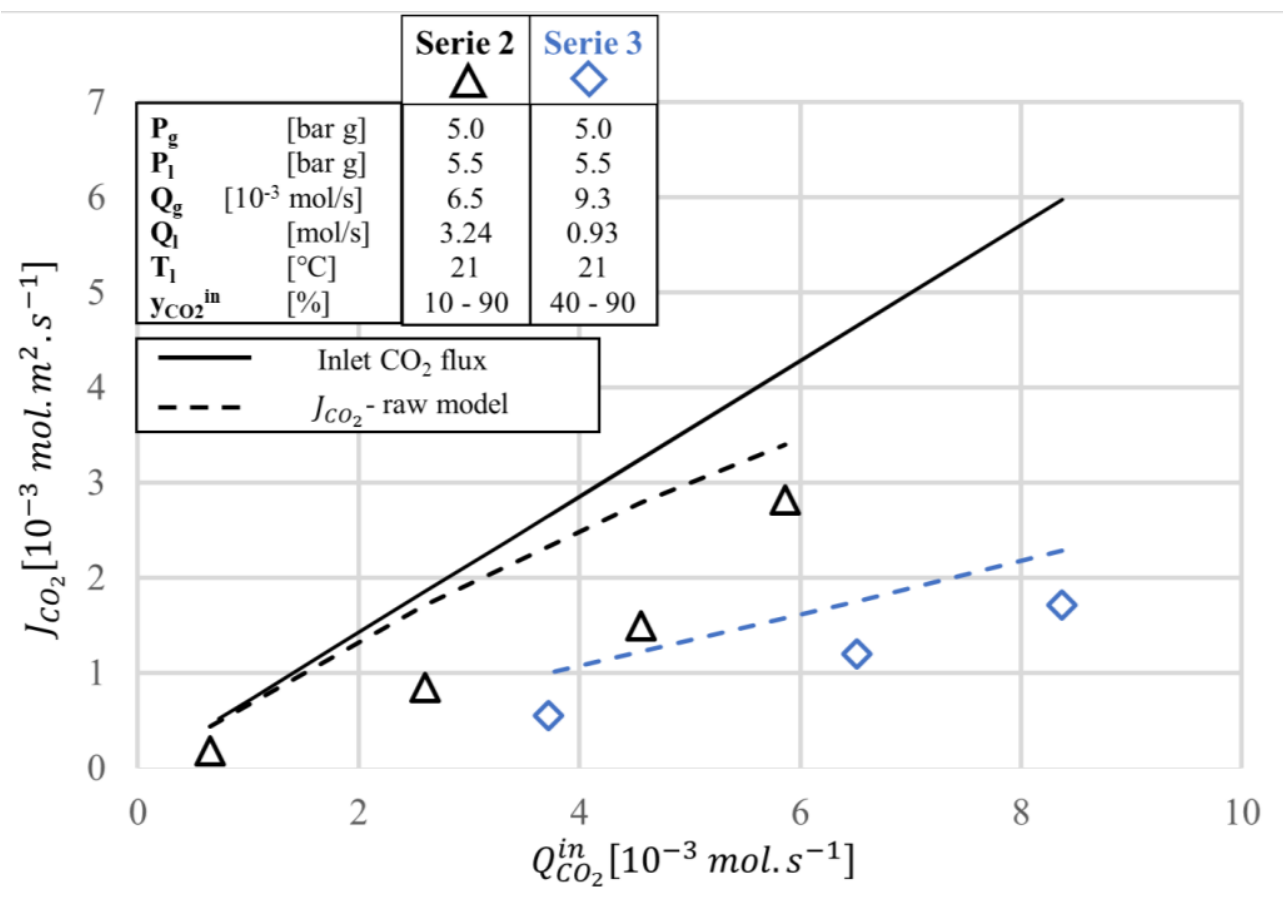

Figure 5 - Influence of the inlet gas composition on the absorbed $\mathrm{CO}_{2}$ flux 
The numerical model had previously been validated for the absorption of pure $\mathrm{CO}_{2}$ into water. However, the comparison in the previous section with experimental data for the case of a $\mathrm{CO}_{2} / \mathrm{CH}_{4}$ binary mixture led to a high deviation in the absorbed $\mathrm{CO}_{2}$ flux. Moreover, this deviation was found to increase with a diminishing $\mathrm{CO}_{2}$ gas fraction. Therefore, there is an additional mass transfer resistance which has not been modelled. Based on these finding; this resistance would both have a constant component and dependent on gas composition. Assuming that the presence of the methane in the gas mixture is not affecting the liquid shellside hydrodynamics, this resistance has to be located in the membrane itself.

\subsection{Knudsen diffusion}

In the membrane, both molecular and Knudsen diffusions are at stake in the membrane pores, with a Knudsen number around 0.34 . The respective diffusivities are calculated in the conditions of the experiments $\left(P_{g}=5 \mathrm{bar} g, T=21^{\circ} \mathrm{C}\right)$. The binary molecular diffusivity is $D_{\mathrm{CO}_{2}-\mathrm{CH}_{4}}=2.93 \times 10^{-6} \mathrm{~m}^{2} . \mathrm{s}^{-1}$ while the Knudsen diffusivity is respectively $3.76 \times 10^{-6} \mathrm{~m}^{2} . \mathrm{s}^{-1}$ and $6.24 \times 10^{-6} \mathrm{~m}^{2} . \mathrm{s}^{-1}$ for $\mathrm{CO}_{2}$ and $\mathrm{CH}_{4}$ respectively. The effective diffusivity of a component $A$ is then calculated from Eq. 18.

$$
\frac{1}{D_{A}^{e f f}}=\frac{1}{D_{A B}}+\frac{1}{D_{A, K n}}
$$

Even though this approach was successfully used by authors, they were working in conditions where the liquid resistance was the limiting one and with membrane exhibiting much larger pores [34,51-53]. Hence this description is in the general case be far too simplistic. Indeed, when the value of the Knudsen number indicates the transfer mode is in the transition zone, the whole classical diffusion equations have to be adapted and solved. In our case, the basic mass transfer equation:

$$
\overrightarrow{N_{A}}=y_{A}\left(\overrightarrow{N_{A}}+\overrightarrow{N_{B}}\right)+\overrightarrow{J_{A}}
$$

Becomes a much more complex one, taking both Knudsen and molecular contributions into account:

$$
\overrightarrow{N_{A}}=y_{A} \frac{D_{A, K n}}{D_{A, K n}+\frac{\varepsilon_{m}}{\tau_{m}} D_{A B}}\left(\overrightarrow{N_{A}}+\overrightarrow{N_{B}}\right)-\left(\frac{1}{\frac{\varepsilon_{m}}{\tau_{m}} D_{A B}}+\frac{1}{D_{A, K n}}\right)^{-1} C_{t o t}^{g} \nabla y_{A}
$$

Luckily, and with the introduction a variable called the separation factor $\alpha$, one can integrate this equation in the membrane phase [54], yielding:

$$
\begin{gathered}
\alpha=-\sqrt{\frac{M_{C O 2}}{M_{C H 4}}} \\
N_{A}^{m}=\frac{\frac{\varepsilon_{m}}{\tau_{m}} D_{A B} C_{\text {tot }}^{g}}{(1+\alpha) d_{l n}} \ln \left(\frac{1-y_{A, m}^{\text {out }}(1+\alpha)+\frac{\frac{\varepsilon_{m}}{\tau_{m}} D_{A B}}{\left(1-y_{A, m}^{\text {in }}(1+\alpha)+{ }^{\frac{\varepsilon_{m}}{\tau_{m}} D_{A B}} / D_{D_{K n, A}}\right.}}{)}\right)
\end{gathered}
$$

As expected from experimental observations, this expression contains both a constant term (associated to Knudsen flow) and term varying with gas composition. Finally, in order to validate this approach, this expression was substituted to the former membrane term in the model before running once again.

\subsection{Advanced model results}

Figure 6 reports the comparison between the new model predictions and the experimental data. Both the trends and the absolute values (average $\varepsilon_{r e l, J_{\mathrm{CO}_{2}}}=6.3 \%$ ) of the three series are well captured by the new model. Despite the good description of the absorbed flux $\mathrm{JCO}_{2}$, significant errors can be observed with different operating conditions (average $\varepsilon_{\mathrm{rel}, \mathrm{JO}_{2}} \mathrm{~min} / \mathrm{max}-34 /+48 \%$ ). They can be explained by three reasons:

- $\quad$ the mass balance precision is limited by the analytical sensors (gas flowmeters and gas composition analysis). This limitation is explained by the wide range of experimental conditions covered $\left(Q_{g}=147-750 \mathrm{NL}_{\mathrm{g}} \mathrm{h}^{-1}, y_{\mathrm{CO}_{2}}^{\text {in }}=10-90 \%\right)$ which induces an increased uncertainty on the sensors; 
- $\quad$ the operating conditions studied in these 3 series fully cover the possibilities of the pilot equipment. Modelling mass transfer is rendered more difficult by such a wide experimental range and the hypothetical change in the mass transfer limiting phenomenon nature;

- no fitting parameter was introduced in the model. Hence, only manufacturer geometrical data were used. As a matter of fact, those parameters are not known with a high confidence, e.g. only one significant digit, ... Increasing the measurement accuracy of those membrane characteristics would improve the model performances.

Considering uncertainty issues and the wide range of operating conditions, the numerical performances obtained with the advanced model are deemed very satisfactory. This is all the more true when one keeps in mind that no fitting factor has been included. Indeed, only membrane geometrical characteristic have been used in this work.

As take home point, this experimental and numerical investigations have highlighted the effect of the gas composition and flow rate on the mass transfer mechanisms: the presence of a methane is not only decreasing the $\mathrm{CO}_{2}$ partial pressure in the gas phase but is also significantly affecting the mass transfer efficiency.

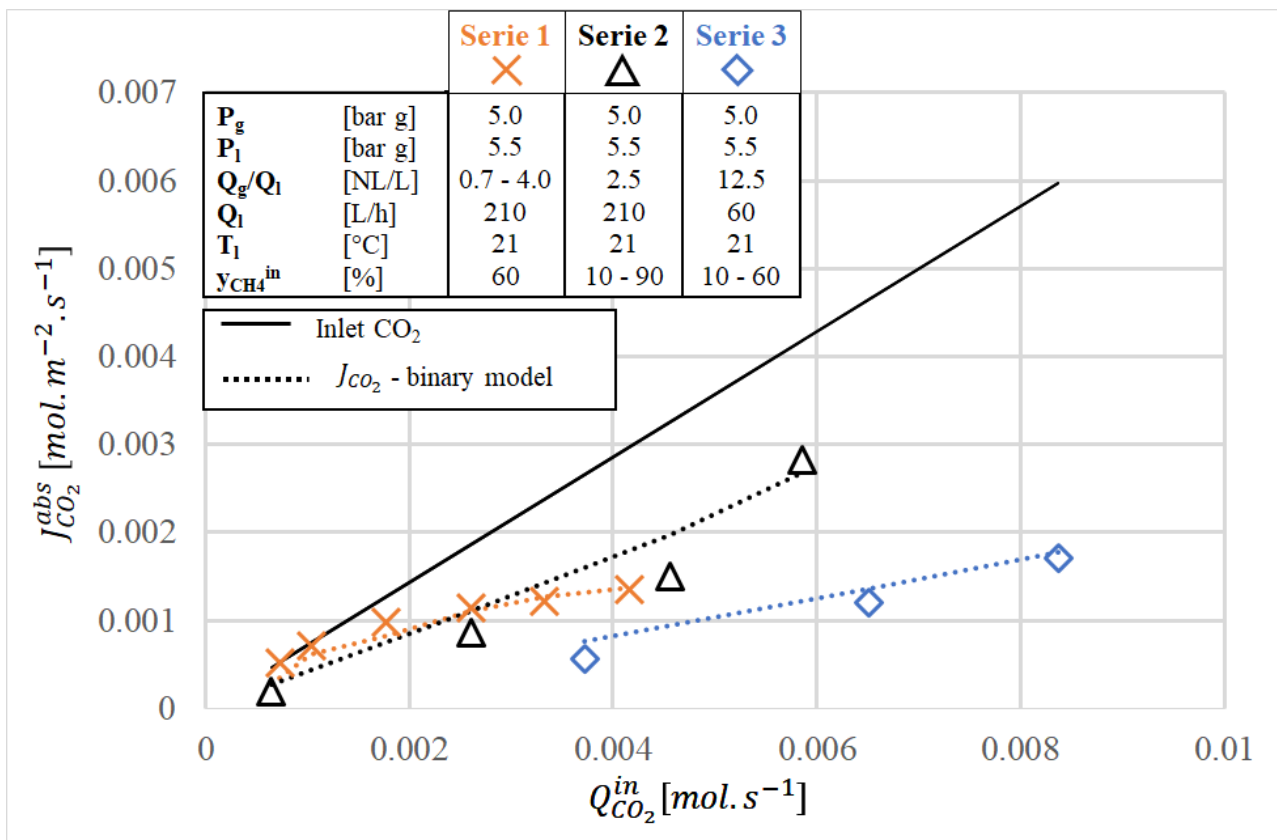

Figure 6 - Advanced model against experimental data: absorbed $\mathrm{CO}_{2}$ flux

\section{Conclusion}

The effect of the gas composition and flow rate on the $\mathrm{CO}_{2}$ physical absorption in a HFMM was experimentally investigated in a $\mathrm{CO}_{2} / \mathrm{CH}_{4}$ mixture in the membrane dry mode. In accordance with the literature, the absorbed $\mathrm{CO}_{2}$ flux is found to increase with an increasing $\mathrm{CO}_{2}$ molar fraction: a factor 15 was found between a $10 \%$ and $90 \% \mathrm{CO}_{2}$ molar fraction at the inlet. This rise in the $\mathrm{CO}_{2}$ partial pressure enhances its solubility, and thus the absorption driving force.

In the meantime, a numerical model describing the absorption of $\mathrm{CO}_{2}$ in a binary gas mixture, based on the internal module geometry and on a local description of the hydrodynamics was proposed. Mass transfer described by a resistance-in-series model was shown not be adapted to properly represent the physics at stake in a HFMM. Indeed, in order to capture the key phenomena, a proper description of mass transfer in transition zone (Knudsen number around 0.34 ) is mandatory. Implementing this description allowed the model to accurately describe mass transfer over a wide range of gas composition and flow rate, without relying on any fitted parameter.

This original numerical model can be of interest to broaden scientific understanding of HFMM mass transfer capabilities. Furthermore, as a multi-scale model, only fed with geometrical parameters, it lays the basis for a future scale-up methodology for HFMM. 


\section{Appendix}

\subsection{Gas diffusion in the membrane}

In a porous media, both molecular and Knudsen diffusions can be at stake. The molecular diffusion also called continuum diffusion refers to the relative motion of different gas species. Knudsen diffusion describes the interactions between the gas molecules and the porous structure: the gas molecule may collide the medium walls more often than other gas molecules. The prevalent diffusion mechanism (molecular and/or Knudsen diffusions) is determined using the Knudsen number $K n$ (Eq. 23). It compares the molecules mean free path $\lambda$ calculated according to the kinetic theory of gases [55] to a characteristic length of the medium microstructure (such as the pore mean diameter $\left.d_{p, \text { mean }}\right)$. The mean free path $\lambda$ represents the average distance one gas molecule can travel before colliding another molecule (Eq. 24).

$$
\begin{gathered}
K n=\frac{\lambda}{d_{p, \text { mean }}} \\
\lambda=\frac{k_{B} T}{\sqrt{2} \pi \eta^{2} P_{g}}
\end{gathered}
$$

with $k_{B}$ the Boltzmann constant $\left[1.3806 \times 10^{-23} \mathrm{~m}^{2} \cdot \mathrm{kg} \cdot \mathrm{s}^{-2} \cdot K^{-1}\right]$, T the temperature $[K], \eta$ the particle hard-shell diameter $[\mathrm{m}]$ and $P_{g}$ the gas pressure $[P a]$.

An example of Knudsen number calculation is provided for $\mathrm{CH}_{4}$ and $\mathrm{CO}_{2}$ diffusion through the X-50 fiber in Table 6 . The particle hard-shell diameters $\eta_{\mathrm{CH}_{4}}=380 \times 10^{-12} \mathrm{~m}$ and $\eta_{\mathrm{CO}_{2}}=390 \times 10^{-12} \mathrm{~m}$ are taken from Hirschfelde [56].

\begin{tabular}{|c|c|c|}
\hline Gas & $\boldsymbol{\lambda}[\mathbf{n m}]$ & $\boldsymbol{K n}$ \\
\hline $\boldsymbol{C H}_{\mathbf{4}}$ & 10.5 & 0.35 \\
\hline $\boldsymbol{C O}_{\mathbf{2}}$ & 9.99 & 0.33 \\
\hline
\end{tabular}

Table 6 - Mean free path and Knudsen number into the porous $\mathrm{X}-50$ fiber $\left(\mathrm{T}=\mathbf{2 9 4} \mathbf{K}, \mathbb{P}_{\mathrm{g}}=\mathbf{5} \mathrm{bar} \mathrm{g}\right.$ )

Under the process conditions, both molecular and Knudsen diffusions are at stake and must be simultaneously considered using Eq. 10.

The effective diffusivity calculated in the above equation is applicable to straight and perfectly cylindrical pores. To account for the porous medium interconnections and the size distribution of the pores, one must take into account the porosity $\varepsilon$ to tortuosity $\tau$ ratio.

$$
D_{A}^{\text {eff,porous }}=\frac{\varepsilon}{\tau} D_{A}^{\text {eff }}
$$

\begin{tabular}{|c|c|c|c|}
\hline Property & Unit & Mathematical expression (SI) & Source \\
\hline $\mathrm{D}_{\mathrm{CO}_{2}-\text { water }}$ & $m^{2} \cdot s^{-1}$ & $5.4711 \times 10^{-15} T \mu_{\text {water }}(T)^{-1.00937}$ & {$[57]$} \\
\hline$D_{\mathrm{CH}_{4}-\text { water }}$ & $m^{2} \cdot s^{-1}$ & $1.1227 \times 10^{-14} T \mu_{\text {water }}(T)^{-0.89297}$ & {$[57]$} \\
\hline$v_{\text {water }}$ & $m^{2} \cdot s^{-1}$ & $10^{-6} \exp \left(-3.28285+\frac{4.56029 \times 10^{2}}{T-1.54576 \times 10^{2}}\right)$ & [58] \\
\hline$D_{\mathrm{CO}_{2}-\mathrm{CH}_{4}}^{g}$ & $m^{2} \cdot s^{-1}$ & $\frac{10^{-7} T^{1.75}}{P\left[\left(\sum v\right)_{A}^{1 / 3}+\left(\sum v\right)_{B}^{1 / 3}\right]^{2}}\left[\frac{1}{M_{A}}+\frac{1}{M_{B}}\right]^{\frac{1}{2}}$ & [59] \\
\hline $\mathrm{H}_{\mathrm{CO}_{2}}^{c c}$ & - & $3.3564 \times 10^{-4} \times R T \times \exp \left(2400\left(\frac{1}{T}-\frac{1}{298.15}\right)\right)$ & {$[50]$} \\
\hline$H_{C H_{4}}^{c c}$ & - & $1.2833 \times 10^{-5} \times R T \times \exp \left(1800\left(\frac{1}{T}-\frac{1}{298.15}\right)\right)$ & {$[50]$} \\
\hline$D_{K n, A}$ & $m^{2} \cdot s^{-1}$ & $\frac{4}{3} d_{\text {pore }} \frac{\varepsilon}{\tau} \sqrt{\frac{R T}{2 \pi M_{A}}}$ & {$[60]$} \\
\hline$\gamma_{\text {water }}$ & N. $m^{-1}$ & $15^{\circ} \mathrm{C}: 73.5 \times 10^{-3}$ & [61] \\
\hline
\end{tabular}

\subsection{Physico-chemical properties}

The developed model requires to estimate physico-chemical properties with a temperature dependence (Table 7). 


\section{$20{ }^{\circ} \mathrm{C}: 73.0 \times 10^{-3}$}

Table 7 - Physico-chemical properties

The empirical Fuller equation is used to estimate binary diffusion coefficients $D_{A B}^{g}$ [59]. The interactions between the molecules are described by the estimation of an equivalent volume of diffusion $\sum v$ based on the elements of the gas molecule. The relative error between the results derived from the Fuller equation and the Chapman-Eskog theory is below $4 \%$ for binary systems [7]. The molecular volumes are taken from Reid [62]. In the case of unavailable data, the molecular volume is estimated by addition of the atomic volumes.

\section{Acknowledgements}

This work was supported by the Marne departmental council, the Champagne-Ardenne regional council and Reims Metropole through the Biotechnology Chair of CentraleSupelec.

\section{Nomenclature}

\section{Latin symbols}

\begin{tabular}{|c|c|}
\hline$a$ & Specific exchange area \\
\hline$C_{i}^{\varphi}$ & $\begin{array}{l}\text { Volumic molar concentration of } \\
\text { component } \mathrm{i} \text { in phase } \varphi\end{array}$ \\
\hline$d$ & Diameter \\
\hline$D_{A}^{\varphi}$ & $\begin{array}{l}\text { Diffusivity of solute } A \text { in the } \\
\text { phase } \varphi\end{array}$ \\
\hline$D_{A B}$ & $\begin{array}{l}\text { Gaseous diffusivity of specie A in } \\
\text { specie B }\end{array}$ \\
\hline$H^{c c}$ & $\begin{array}{l}\text { Henry coefficient relative to } \\
\text { liquid and gas molar } \\
\text { concentrations }\end{array}$ \\
\hline$J_{\mathrm{i}}^{a b s}$ & $\begin{array}{l}\text { Absorbed flux of component } \mathrm{i} \\
\text { through the membrane }\end{array}$ \\
\hline$K n$ & Knudsen number \\
\hline$K_{\varphi, i}^{0}$ & $\begin{array}{l}\text { Overall mass transfer coefficient } \\
\text { of specie i relative to the phase } \\
\varphi \text { in mol. } m^{-2} . s^{-1}\end{array}$ \\
\hline$K_{\varphi, i}$ & $\begin{array}{l}\text { Overall mass transfer coefficient } \\
\text { of specie i relative to the phase } \\
\varphi \text { in } m . s^{-1}\left(i=\mathrm{CO}_{2} \text { if not }\right. \\
\text { specified) }\end{array}$ \\
\hline$k_{\varphi, i}$ & $\begin{array}{l}\text { Mass transfer coefficient of } \\
\text { specie i relative to the resistance } \\
\text { of the phase } \varphi \text { in } m . s^{-1}\end{array}$ \\
\hline$L_{f}$ & Length of the fiber \\
\hline$M_{i}$ & Molar mass of specie i \\
\hline$\vec{n}$ & Normal vector \\
\hline$N_{A}$ & Molar flux of specie A \\
\hline
\end{tabular}

\begin{tabular}{|cl|}
\hline$N_{f}$ & Number of fibers \\
$P_{i}$ & Gas partial pressure of \\
& component $\mathrm{i}$ \\
$P_{\varphi}$ & Total pressure of phase $\varphi$ \\
$\Delta P$ & Transmembrane pressure \\
$Q_{g}$ & Gas volumetric flowrate \\
$Q_{l}$ & Liquid flowrate \\
$r$ & Radius \\
$r_{i}$ & Source term of specie $\mathrm{i}$ \\
$R$ & Ideal gas constant \\
$R_{i} / R_{O}$ & Inner/Outer radius of the fiber \\
$R_{C H_{4}}$ & bundle \\
$R_{\varphi}$ & Methane recovery ratio \\
$R e$ & Mass transfer resistance of the \\
$S$ & Reynolds number \\
$S c$ & Schange area \\
$S h$ & Sherwood number \\
$T_{\varphi}$ & Temperature of phase $\varphi$ \\
$u_{\varphi}$ & Velocity of the phase $\varphi$ \\
$x_{i}$ & Molar fraction of component $\mathrm{i}$ in \\
$y_{i}$ & the liquid phase \\
& the gas phase \\
\hline &
\end{tabular}

\section{Greek symbols}




\begin{tabular}{|cl|}
\hline$\alpha$ & Separation factor \\
$\gamma$ & Surface tension \\
$\delta$ & Thickness \\
$\varepsilon$ & Porosity \\
$\varepsilon_{\text {bed, } \varphi}$ & Porosity of the porous medium \\
& related to phase $\varphi$ \\
$\varepsilon_{r e l}$ & Relative error \\
$\frac{\eta}{\overline{\kappa_{\varphi}}}$ & Membrane wetting fraction \\
& Permeability tensor of the \\
& porous medium related to \\
& phase $\varphi$ \\
\hline
\end{tabular}

\section{Superscripts}

\begin{tabular}{|cl|}
\hline abs & Relative to the absorbed flow \\
bulk & Relative to the bulk \\
eff & Effective \\
in & Relative to the inlet flow of the \\
& HFMM
\end{tabular}

\section{Subscripts}

\begin{tabular}{|cl|}
\hline bed & Relative to the porous medium \\
break & Breakthrough pressure \\
$\mathrm{CH}_{4}$ & Methane \\
$\mathrm{CO}_{2}$ & Carbon dioxide \\
$\exp$ & Relative to the experiment \\
$f i$ & Relative to the hollow fiber \\
& inner side \\
fiber & Relative to the hollow fiber \\
\hline
\end{tabular}

\begin{tabular}{|cl|}
\hline$\lambda$ & Molecule mean free path \\
$\Phi$ & Packing fraction in the bundle \\
& of fibers (\%) \\
$\mu_{\varphi}$ & Dynamic viscosity of phase $\varphi$ \\
$v$ & Kinematic viscosity \\
$\rho$ & Volumetric mass density \\
$\tau$ & Tortuosity \\
\hline
\end{tabular}

$\begin{array}{ll}\text { out } & \begin{array}{l}\text { Relative to the outlet flow of } \\ \text { the HFMM }\end{array}\end{array}$

\begin{tabular}{|cl|}
\hline$f o$ & Relative to the hollow fiber \\
& outer side \\
$m$ & Relative to the membrane \\
num & Relative to the numerical model \\
$M L$ & Logarithmic mean \\
$p$ & Relative to the pore \\
tot & Total \\
\hline
\end{tabular}




\section{References}

[1] M.H. Al-Marzouqi, S.A.M. Marzouk, N. Abdullatif, High pressure removal of acid gases using hollow fiber membrane contactors: Further characterization and long-term operational stability, J. Nat. Gas Sci. Eng. 37 (2017) 192-198. doi:10.1016/j.jngse.2016.11.039.

[2] S. Zhao, P.H.M. Feron, L. Deng, E. Favre, E. Chabanon, S. Yan, J. Hou, V. Chen, H. Qi, Status and progress of membrane contactors in post-combustion carbon capture: A state-of-the-art review of new developments, J. Membr. Sci. 511 (2016) 180-206. doi:10.1016/j.memsci.2016.03.051.

[3] P.H.M. Feron, Absorption-Based Post-Combustion Capture of Carbon Dioxide, Woodhead Publishing, 2016.

[4] A. McLeod, B. Jefferson, E.J. McAdam, Quantifying the loss of methane through secondary gas mass transport (or "slip") from a micro-porous membrane contactor applied to biogas upgrading, Water Res. 47 (2013) 3688-3695. doi:10.1016/j.watres.2013.04.032.

[5] S. Vogler, A. Braasch, G. Buse, S. Hempel, J. Schneider, M. Ulbricht, Biogas Conditioning Using Hollow Fiber Membrane Contactors, Chemie Ingenieur Technik. 58 (2013) 1254-1258. doi:10.1002/cite.201200235.

[6] A.C. Sun, W. Kosar, Y. Zhang, X. Feng, Vacuum membrane distillation for desalination of water using hollow fiber membranes, J. Membr. Sci. 455 (2014) 131-142. doi:10.1016/j.memsci.2013.12.055.

[7] M. Roustan, Transferts gaz-liquide dans les procédés de traitement des aux et des effluents gazeux, Tec \& Doc, 2003.

[8] J. Elhajj, M. Al-Hindi, F. Azizi, A Review of the Absorption and Desorption Processes of Carbon Dioxide in Water Systems, Ind. Eng. Chem. Res. 53 (2014) 2-22. doi:10.1021/ie403245p.

[9] E.L. Paul, V.A. Atiemo-Obeng, S.M. Kresta, eds., Handbook of industrial mixing: science and practice, Wiley-Interscience, Hoboken, N.J, 2004.

[10] P. Luis, B. Van der Bruggen, T. Van Gerven, Non-dispersive absorption for $\mathrm{CO} 2$ capture: from the laboratory to industry, J. Chem. Technol. Biotechnol. 86 (2011) 769-775. doi:10.1002/jctb.2614.

[11] J. Kerber, J.-U. Repke, Mass transfer and selectivity analysis of a dense membrane contactor for upgrading biogas, J. Membr. Sci. 520 (2016) 450-464. doi:10.1016/j.memsci.2016.08.008.

[12] D. Albarracin Zaidiza, Modelling of Hollow Fibre Membrane Contactors : Application Postcombustion Carbon Dioxide Capture, Université de Lorraine, LRGP, 2016. http://www.theses.fr/2016LORR0035.

[13] S. Masoumi, M.R. Rahimpour, M. Mehdipour, Removal of carbon dioxide by aqueous amino acid salts using hollow fiber membrane contactors, J. CO2 Util. 16 (2016) 42-49. doi:10.1016/j.jcou.2016.05.008.

[14] G. Hu, N.J. Nicholas, K.H. Smith, K.A. Mumford, S.E. Kentish, G.W. Stevens, Carbon dioxide absorption into promoted potassium carbonate solutions: A review, Int. J. Greenh. Gas Control. 53 (2016) 28-40. doi:10.1016/j.ijggc.2016.07.020.

[15] D. deMontigny, P. Tontiwachwuthikul, A. Chakma, Comparing the Absorption Performance of Packed Columns and Membrane Contactors, Ind. Eng. Chem. Res. 44 (2005) 5726-5732. doi:10.1021/ie040264k.

[16] W. Rongwong, C. Fan, Z. Liang, Z. Rui, R.O. Idem, P. Tontiwachwuthikul, Investigation of the effects of operating parameters on the local mass transfer coefficient and membrane wetting in a membrane gas absorption process, J. Membr. Sci. 490 (2015) 236-246. doi:10.1016/j.memsci.2015.04.071.

[17] H. Gao, S. Liu, G. Gao, X. Luo, Z. Liang, Hybrid behavior and mass transfer performance for absorption of $\mathrm{CO} 2$ into aqueous DEEA/PZ solutions in a hollow fiber membrane contactor, Sep. Purif. Technol. 201 (2018) 291-300. doi:10.1016/j.seppur.2018.03.027. 
[18] K. Kim, D.Y. Kim, K.R. Lee, J.-I. Han, Electricity generation from iron EDTA-based liquid redox sulfur recovery process with enhanced stability of EDTA, Energy Convers. Manag. 76 (2013) 342-346. doi:10.1016/j.enconman.2013.07.063.

[19] Z. Zhang, Y. Yan, L. Zhang, Y. Chen, J. Ran, G. Pu, C. Qin, Theoretical Study on CO2 Absorption from Biogas by Membrane Contactors: Effect of Operating Parameters, Ind. Eng. Chem. Res. 53 (2014) 14075-14083. doi:10.1021/ie502830k.

[20] M.H. Al-Marzouqi, M.H. El-Naas, S.A.M. Marzouk, M.A. Al-Zarooni, N. Abdullatif, R. Faiz, Modeling of absorption of $\mathrm{CO} 2$ in membrane contactors, Sep. Purif. Technol. 59 (2008) 286293. doi:10.1016/j.seppur.2007.06.020.

[21] S. Atchariyawut, R. Jiraratananon, R. Wang, Separation of $\mathrm{CO} 2$ from $\mathrm{CH} 4$ by using gas-liquid membrane contacting process, J. Membr. Sci. 304 (2007) 163-172. doi:10.1016/j.memsci.2007.07.030.

[22] Z. Zhang, Comparisons of various absorbent effects on carbon dioxide capture in membrane gas absorption (MGA) process, 2016.

[23] Z. Zhang, F. Chen, M. Rezakazemi, W. Zhang, C. Lu, H. Chang, X. Quan, Modeling of a CO2Piperazine-Membrane Absorption System, 2017.

[24] M. Mavroudi, S.P. Kaldis, G.P. Sakellaropoulos, A study of mass transfer resistance in membrane gas-liquid contacting processes, J. Membr. Sci. 272 (2006) 103-115. doi:10.1016/j.memsci.2005.07.025.

[25] S.-J. Kim, A. Park, S.-E. Nam, Y.-I. Park, P.S. Lee, Practical designs of membrane contactors and their performances in CO2/CH4 separation, Chem. Eng. Sci. 155 (2016) 239-247. doi:10.1016/j.ces.2016.08.018.

[26] A. Park, Y.M. Kim, J.F. Kim, P.S. Lee, Y.H. Cho, H.S. Park, S.E. Nam, Y.I. Park, Biogas upgrading using membrane contactor process: Pressure-cascaded stripping configuration, Sep. Purif. Technol. 183 (2017) 358-365. doi:10.1016/j.seppur.2017.03.006.

[27] F. Porcheron, S. Drozdz, Hollow fiber membrane contactor transient experiments for the characterization of gas/liquid thermodynamics and mass transfer properties, Chem. Eng. Sci. 64 (2009) 265-275. doi:10.1016/j.ces.2008.09.035.

[28] H.-Y. Zhang, R. Wang, D.T. Liang, J.H. Tay, Modeling and experimental study of CO2 absorption in a hollow fiber membrane contactor, J. Membr. Sci. 279 (2006) 301-310. doi:10.1016/j.memsci.2005.12.017.

[29] S.A.M. Marzouk, M.H. Al-Marzouqi, M. Teramoto, N. Abdullatif, Z.M. Ismail, Simultaneous removal of $\mathrm{CO} 2$ and $\mathrm{H} 2 \mathrm{~S}$ from pressurized $\mathrm{CO} 2-\mathrm{H} 2 \mathrm{~S}-\mathrm{CH} 4$ gas mixture using hollow fiber membrane contactors, Sep. Purif. Technol. 86 (2012) 88-97. doi:10.1016/j.seppur.2011.10.024.

[30] V. Fougerit, V. Pozzobon, D. Pareau, M.-A. Théoleyre, M. Stambouli, Gas-liquid absorption in industrial cross-flow membrane contactors: Experimental and numerical investigation of the influence of transmembrane pressure on partial wetting, Chem. Eng. Sci. 170 (2017) 561-573. doi:10.1016/j.ces.2017.03.042.

[31] J.-G. Lu, Y.-F. Zheng, M.-D. Cheng, Wetting mechanism in mass transfer process of hydrophobic membrane gas absorption, J. Membr. Sci. 308 (2008) 180-190. doi:10.1016/j.memsci.2007.09.051.

[32] S. Boributh, W. Rongwong, S. Assabumrungrat, N. Laosiripojana, R. Jiraratananon, Mathematical modeling and cascade design of hollow fiber membrane contactor for $\mathrm{CO} 2$ absorption by monoethanolamine, J. Membr. Sci. 401-402 (2012) 175-189. doi:10.1016/j.memsci.2012.01.048.

[33] V.Y. Dindore, D.W.F. Brilman, G.F. Versteeg, Modelling of cross-flow membrane contactors: physical mass transfer processes, J. Membr. Sci. 251 (2005) 209-222. doi:10.1016/j.memsci.2004.11.017.

[34] H. Kreulen, C.A. Smolders, G.F. Versteeg, W.P.M. van Swaaij, Microporous hollow fibre membrane modules as gas-liquid contactors Part 2. Mass transfer with chemical reaction, J. Membr. Sci. 78 (1993) 217-238. doi:10.1016/0376-7388(93)80002-F. 
[35] K. Li, D. Wang, C.C. Koe, W.K. Teo, Use of asymmetric hollow fibre modules for elimination of H2S from gas streams via a membrane absorption method, Chem. Eng. Sci. 53 (1998) 11111119. doi:10.1016/S0009-2509(97)00343-6.

[36] Y. Qin, J.M. Cabral, others, Lumen mass transfer in hollow-fiber membrane processes with constant external resistances, AIChE J.-Am. Inst. Chem. Eng. 43 (1997) 1975-1987.

[37] N. Goyal, S. Suman, S.K. Gupta, Mathematical modeling of $\mathrm{CO} 2$ separation from gaseousmixture using a Hollow-Fiber Membrane Module: Physical mechanism and influence of partialwetting, J. Membr. Sci. 474 (2015) 64-82. doi:10.1016/j.memsci.2014.09.036.

[38] Y. Yan, Z. Zhang, L. Zhang, Y. Chen, Q. Tang, Dynamic Modeling of Biogas Upgrading in Hollow Fiber Membrane Contactors, Energy Fuels. 28 (2014) 5745-5755. doi:10.1021/ef501435q.

[39] A. Malek, K. Li, W.K. Teo, Modeling of Microporous Hollow Fiber Membrane Modules Operated under Partially Wetted Conditions, Ind. Eng. Chem. Res. 36 (1997) 784-793. doi:10.1021/ie960529y.

[40] G. Pantoleontos, S.P. Kaldis, D. Koutsonikolas, G. Skodras, G.P. Sakellaropoulos, Analytical and Numerical Solutions of the Mass Continuity Equation in the Lumen Side of a Hollow-Fiber Membrane Contactor with Linear or Nonlinear Boundary Conditions, Chem. Eng. Commun. 197 (2010) 709-732. doi:10.1080/00986440903288039.

[41] G. Pantoleontos, T. Theodoridis, M. Mavroudi, E.S. Kikkinides, D. Koutsonikolas, S.P. Kaldis, A.E. Pagana, Modelling, simulation, and membrane wetting estimation in gas-liquid contacting processes, Can. J. Chem. Eng. 95 (2017) 1352-1363. doi:10.1002/cjce.22790.

[42] E. Chabanon, D. Roizard, E. Favre, Modeling strategies of membrane contactors for postcombustion carbon capture: A critical comparative study, Chem. Eng. Sci. 87 (2013) 393-407. doi:10.1016/j.ces.2012.09.011.

[43] K.A. Hoff, H.F. Svendsen, Membrane contactors for $\mathrm{CO} 2$ absorption - Application, modeling and mass transfer effects, Chem. Eng. Sci. 116 (2014) 331-341. doi:10.1016/j.ces.2014.05.001.

[44] D. Albarracin Zaidiza, B. Belaissaoui, S. Rode, T. Neveux, C. Makhloufi, C. Castel, D. Roizard, E. Favre, Adiabatic modelling of $\mathrm{CO} 2$ capture by amine solvents using membrane contactors, J. Membr. Sci. 493 (2015) 106-119. doi:10.1016/j.memsci.2015.06.015.

[45] V.I. Roldugin, A.A. Shutova, A.V. Volkov, E.L.V. Goetheer, V.V. Volkov, Kinetics of carbon dioxide removal from water in flat membrane contactor, Pet. Chem. 54 (2014) 507-514. doi:10.1134/S0965544114070111.

[46] V. Fougerit, Développement d'un procédé innovant d'épuration du biogaz par mise en oeuvre de contacteurs à membranes, Université Paris-Saclay, 2017. http://www.theses.fr/2017SACLC053/document.

[47] Y. Lv, X. Yu, S.-T. Tu, J. Yan, E. Dahlquist, Wetting of polypropylene hollow fiber membrane contactors, J. Membr. Sci. 362 (2010) 444-452. doi:10.1016/j.memsci.2010.06.067.

[48] A. Dupuy, Stabilisation de l'inerface liquide-liquide dans un contacteur membranaire : application à l'extraction sélective de terpènes oxygénés d'huiles essentielles d'agrumes, AgroParisTech, 2010.

140 [49] A. Sengupta, P.A. Peterson, B.D. Miller, J. Schneider, C.W. Fulk Jr, Large-scale application of membrane contactors for gas transfer from or to ultrapure water, Sep. Purif. Technol. 14 (1998) 189-200.

[50] R. Sander, Compilation of Henry's law constants, version 3.99, Atmospheric Chem. Phys. Discuss. 14 (2014) 29615-30521. doi:10.5194/acpd-14-29615-2014.

[51] H. Kreulen, C.A. Smolders, G.F. Versteeg, W.P.M. van Swaaij, Microporous hollow fibre membrane modules as gas-liquid contactors. Part 1. Physical mass transfer processes: A specific application: Mass transfer in highly viscous liquids, J. Membr. Sci. 78 (1993) 197-216. doi:10.1016/0376-7388(93)80001-E.

[52] J. Xu, R. Li, L. Wang, J. Li, X. Sun, Removal of benzene from nitrogen by using polypropylene hollow fiber gas-liquid membrane contactor, Sep. Purif. Technol. 68 (2009) 75-82. doi:10.1016/j.seppur.2009.04.010. 
[53] Y.-T. Zhang, X.-G. Dai, G.-H. Xu, L. Zhang, H.-Q. Zhang, J.-D. Liu, H.-L. Chen, Modeling of CO2 mass transport across a hollow fiber membrane reactor filled with immobilized enzyme, AIChE J. 58 (2012) 2069-2077. doi:10.1002/aic.12732.

[54] W. Kast, C.-R. Hohenthanner, Mass transfer within the gas-phase of porous media, Int. J. Heat Mass Transf. 43 (2000) 807-823. doi:10.1016/S0017-9310(99)00158-1.

[55] R.B. Bird, W.E. Stewart, E. Lightfoot, Transport Phenomena, 2nd edition, John Wiley \& Sons, Inc., 2002.

[56] J.O. Hirschfelde, C.F. Curtiss, R.B. Bird, Molecular theory of gases and liquids, J. Polym. Sci. 17 (1954) 116-116. doi:10.1002/pol.1955.120178311.

[57] A.L. Magalhães, P.F. Lito, F.A. Da Silva, C.M. Silva, Simple and accurate correlations for diffusion coefficients of solutes in liquids and supercritical fluids over wide ranges of temperature and density, J. Supercrit. Fluids. 76 (2013) 94-114. doi:10.1016/j.supflu.2013.02.002.

[58] C.H. Hsu, H.M. Li, Viscosity of aqueous blended amines, J. Chem. Eng. Data. 42 (1997) 714-720.

[59] E.N. Fuller, P.D. Schettler, J.C. Giddings, New method for prediction of binary gas-phase diffusion coefficients, Ind. Eng. Chem. 58 (1966) 18-27.

[60] M.-C. Yang, E.L. Cussler, Designing hollow-fiber contactors, AIChE J. 32 (1986) 1910-1916.

[61] J.L. Pérez-Díaz, M.A. Álvarez-Valenzuela, J.C. García-Prada, The effect of the partial pressure of water vapor on the surface tension of the liquid water-air interface, J. Colloid Interface Sci. 381 (2012) 180-182. doi:10.1016/j.jcis.2012.05.034.

[62] R.C. Reid, J.M. Prausnitz, B.E. Poling, The Properties of Gases and Liquids, 4th edition, McGrawHill Inc., New York, 1987. 